\title{
Uranyl Ion-Containing Polymeric Assemblies with cis/trans Isomers of 1,2-, 1,3- and 1,4-Cyclohexanedicarboxylates, Including a Helical Chain and a Sixfold-Interpenetrated Framework
}

\author{
Pierre Thuéry*,† and Jack Harrowfield ${ }^{*,+}$ \\ †NIMBE, CEA, CNRS, Université Paris-Saclay, CEA Saclay, 91191 Gif-sur-Yvette, France \\ †ISIS, Université de Strasbourg, 8 allée Gaspard Monge, 67083 Strasbourg, France
}

\begin{abstract}
Diverse isomers of cyclohexanedicarboxylic acid $\left(\mathrm{chdcH}_{2}\right)$ have been used to synthesize uranyl ion complexes in the presence of various possible counterions and, but for one case, under (solvo-)hydrothermal conditions. The cis isomer of 1,2-chdc $\mathrm{H}_{2}$ gives the complex $\left[\mathrm{UO}_{2}\left(c-1,2\right.\right.$-chdc) $\left.\left(\mathrm{H}_{2} \mathrm{O}\right)_{2}\right] \cdot \mathrm{H}_{2} \mathrm{O}(\mathbf{1})$, which crystallizes as an enantiomerically pure helical monoperiodic structure, while partial isomerization of the cis into the trans form yields $\left[\mathrm{PPh}_{4}\right]_{2}\left[\left(\mathrm{UO}_{2}\right)_{3}(c-1,2 \text {-chdc })_{3}(\right.$ rac-t-1,2-chdc $\left.)\left(\mathrm{H}_{2} \mathrm{O}\right)\right] \cdot 2 \mathrm{H}_{2} \mathrm{O}(2)$, a ladderlike monoperiodic assembly. The pure $(1 R, 2 R)$ enantiomer of $t-1,2-$ chdc $_{2}$ gives $\left[\mathrm{UO}_{2}\left(R-t-1,2\right.\right.$-chdc) $\left.\left(\mathrm{H}_{2} \mathrm{O}\right)\right]$ (3) containing a diperiodic assembly of hcb topological type. When reacted at room temperature, its racemic counterpart produces $\left[\mathrm{UO}_{2}(\mathrm{rac}-\mathrm{t}-1,2-\right.$ chdc)(EtOH)] $\cdot \mathrm{H}_{2} \mathrm{O}(\mathbf{4})$, a diperiodic species with the fes topological type isomorphous to other similar solvates. Using a mixture of the cis and trans isomers of 1,3-chdcH ${ }_{2}$ gives $\left[\mathrm{NH}_{4}\right]\left[\mathrm{NBu}_{4}\right]\left[\left(\mathrm{UO}_{2}\right)_{2}(c-1,3 \text {-chdc })_{2}(t-1,3-\right.$ chdc $\left.)\right](\mathbf{5})$, the first instance of a triperiodic uranyl-containing framework obtained with this ligand. Finally, the complex $\left[\mathrm{H}_{2} \mathrm{NMe}_{2}\right]_{2}\left[\left(\mathrm{UO}_{2}\right)_{2}(t-1,4-\mathrm{chdc})_{3}\right](6)$, containing the trans isomer of 1,4-chdc ${ }^{2-}$, crystallizes as a triperiodic framework with ths topology, and displays sixfold-interpenetration, the highest degree found up to now in a uranyl ion complex. These results are discussed together with previous ones obtained with this highly versatile family of cyclohexanedicarboxylate ligands.
\end{abstract}




\section{INTRODUCTION}

Among the many polycarboxylate families which have been used in the synthesis of uranyl-organic assemblies, ${ }^{1-5}$ that of cyclohexanedicarboxylates appears to be a particularly versatile one, owing to the existence of three positional isomers $\left(1,2-, 1,3-\right.$ and $\left.1,4-\operatorname{chdc}^{2-}\right)$, each of them existing in the cis or trans forms, some of them being chiral, with the possibility of axial or equatorial positioning of the carboxylate groups. This gives rise to a large range of ligand geometry and connectivity and, in this respect, this family is more diverse than its aromatic counterpart comprised of only the three positional isomers of benzenedicarboxylate. Due to the proximity of the two coordination sites, $1,2-\mathrm{chdc}^{2-}$ is well suited to the formation of polynuclear, closed molecular species, and this has effectively been observed in a series of tetrahedral uranyl clusters held by the trans isomer $t-1,2-$ chdc $^{2-}$, either in its racemic or its enantiomerically pure $(1 R, 2 R)$ form, ${ }^{6,7}$ and also in an octanuclear uranyl cage involving the $c i s$ isomer $c-1,2-\operatorname{chdc}^{2-} .8$ At the other end of the series, both the $c i s$ and trans isomers of 1,4-chdc ${ }^{2-}$ are divergent ligands which have been found to give mono-, di- or triperiodic assemblies (denoted one-, two- or three-dimensional, 1D, 2D or 3D, for convenience) with in the latter case rings sufficiently large to enable network interpenetration. ${ }^{9}$ The formation of all these species, using (solvo-)hydrothermal methods, is highly dependent on the choice of the experimental conditions, and in particular on the nature of the counterions when the uranyl complexes are anionic, as is often the case. Modulating the counterions over a wide range, from the small $\mathrm{NH}_{4}{ }^{+}$or alkali metal cations up to the large $\mathrm{PPh}_{4}{ }^{+}$or macrocyclic metal ion complexes has allowed the isolation of varied polymeric species, $1 \mathrm{D}, 2 \mathrm{D}$ or $3 \mathrm{D} \cdot{ }^{6-12}$ Considering the number of parameters involved, mainly related to ligand geometry and structure-directing effects of the counterions, that exert a possible influence on the connectivity in the final product, prediction of the outcome can only be conjectural. As a continuation of this work, we have now determined the 
crystal structure of six uranyl ion complexes involving either $c-1,2-\operatorname{chdc}^{2-}$, a mixture of $c$ - and $t$ 1,2-chdc ${ }^{2-}$, the pure $(1 R, 2 R)-t-1,2-\operatorname{chdc}^{2-}$ enantiomer, $c-1,3-\operatorname{chdc}^{2-}$ or $t-1,4-\operatorname{chdc}^{2-}$. Some of these complexes are neutral, while others are anionic and contain diverse counterions. Overall, they provide an assortment of very different structures which give a more nearly complete spectrum of the species which can be obtained with these ligands and that we place within the context of our work with cyclohexanedicarboxylates in its entirety.

\section{EXPERIMENTAL SECTION}

Syntheses. Caution! Uranium is a radioactive and chemically toxic element, and uraniumcontaining samples must be handled with suitable care and protection.

$\mathrm{UO}_{2}\left(\mathrm{NO}_{3}\right)_{2} \cdot 6 \mathrm{H}_{2} \mathrm{O}$ (depleted uranium, R. P. Normapur, 99\%) was purchased from Prolabo, 1,3-cyclohexanedicarboxylic acid $\left(c / t-1,3-\mathrm{chdcH}_{2}\right.$, mixture of cis and trans isomers) and 1,4cyclohexanedicarboxylic acid $\left(c / t-1,4-\mathrm{chdcH}_{2}\right.$, mixture of cis and trans isomers) were from Aldrich, cis-1,2-cyclohexanedicarboxylic acid $\left(c-1,2-\mathrm{chdcH}_{2}\right) \quad$ and trans-1,4cyclohexanedicarboxylic acid $\left(t-1,4-\mathrm{chdcH}_{2}\right)$ were from Alfa Aesar, rac-trans-1,2cyclohexanedicarboxylic acid $\left(r a c-t-1,2-\mathrm{chdcH}_{2}\right)$ was from Lancaster. The $(1 R, 2 R)$ enantiomer of $t$-1,2-chdcH $\mathrm{C}_{2}$, denoted $R$ - $t-1,2-\mathrm{chdcH}_{2}$, was isolated through crystallization with $(R)-1-$ phenylethylamine as a resolving agent, as in the literature, ${ }^{13}$ although both the $(1 R, 2 R)$ and $(1 S, 2 S)$ enantiomers are also available commercially. For all syntheses under (solvo-)hydrothermal conditions (all complexes except 4), the mixtures in demineralized water were placed in $10 \mathrm{~mL}$ tightly closed glass vessels and heated at $140{ }^{\circ} \mathrm{C}$ under autogenous pressure. 
$\left[\mathrm{UO}_{2}(c-1,2-\mathrm{chdc})\left(\mathrm{H}_{2} \mathrm{O}\right)_{2}\right] \cdot \mathrm{H}_{2} \mathrm{O}$ (1). c-1,2-chdcH $\mathrm{H}_{2}(17 \mathrm{mg}, 0.10 \mathrm{mmol}), \mathrm{UO}_{2}\left(\mathrm{NO}_{3}\right)_{2} \cdot 6 \mathrm{H}_{2} \mathrm{O}(35$ mg, $0.07 \mathrm{mmol}), \mathrm{LiNO}_{3}(7 \mathrm{mg}, 0.10 \mathrm{mmol})$, and 18-crown-6 (26 mg, $\left.0.10 \mathrm{mmol}\right)$ were dissolved in water $(0.8 \mathrm{~mL})$. Yellow crystals of complex 1 were obtained in low yield within two months.

$\left[\mathrm{PPh}_{4}\right]_{2}\left[\left(\mathrm{UO}_{2}\right)_{3}(c-1,2-c h d c)_{3}(\mathrm{rac}-\mathrm{t}-1,2-\mathrm{chdc})\left(\mathrm{H}_{2} \mathrm{O}\right)\right] \cdot 2 \mathrm{H}_{2} \mathrm{O}$ (2). $c-1,2-\mathrm{chdcH}_{2} \quad(17 \mathrm{mg}, 0.10$ $\mathrm{mmol}), \mathrm{UO}_{2}\left(\mathrm{NO}_{3}\right)_{2} \cdot 6 \mathrm{H}_{2} \mathrm{O}(35 \mathrm{mg}, 0.07 \mathrm{mmol})$, and $\mathrm{PPh} 4 \mathrm{Br}(42 \mathrm{mg}, 0.10 \mathrm{mmol})$ were dissolved in water $(0.8 \mathrm{~mL})$ and acetonitrile $(0.2 \mathrm{~mL})$. Yellow crystals of complex 2 were obtained in very low yield within three months, mixed with crystals of the octanuclear cage species $\left[\mathrm{NH}_{4}\right]\left[\mathrm{PPh}_{4}\right]\left[\left(\mathrm{UO}_{2}\right)_{8}(c \text {-chdc })_{9}\left(\mathrm{H}_{2} \mathrm{O}\right)_{6}\right] \cdot 3 \mathrm{H}_{2} \mathrm{O}$ previously reported. ${ }^{8}$

$\left[\cup \mathrm{O}_{2}(R-t-1,2-c h d c)\left(\mathrm{H}_{2} \mathrm{O}\right)\right]$ (3). $R-t-1,2-\mathrm{chdcH}_{2}(17 \mathrm{mg}, 0.10 \mathrm{mmol}), \mathrm{UO}_{2}\left(\mathrm{NO}_{3}\right)_{2} \cdot 6 \mathrm{H}_{2} \mathrm{O}(35$ $\mathrm{mg}, 0.07 \mathrm{mmol})$, and $\mathrm{KNO}_{3}(20 \mathrm{mg}, 0.20 \mathrm{mmol})$ were dissolved in water $(1.2 \mathrm{~mL})$. Yellow crystals of complex $\mathbf{3}$ were obtained in low yield within two months.

$\left[\mathrm{UO}_{2}(\mathrm{rac}-\mathrm{t}-1,2-\mathrm{chdc})(\mathrm{EtOH})\right] \cdot \mathrm{H}_{2} \mathrm{O}$ (4). $\mathrm{UO}_{2}(\mathrm{OAc})_{2} \cdot 2 \mathrm{H}_{2} \mathrm{O}(83 \mathrm{mg}, 0.20 \mathrm{mmol})$ and $\mathrm{rac}-\mathrm{t}-1,2-$ chdcH $\mathrm{H}_{2}(51 \mathrm{mg}, 0.30 \mathrm{mmol})$ were heated $\left(80^{\circ} \mathrm{C}\right)$ and stirred in a mixture of water $(2 \mathrm{~mL})$ and ethanol $(1 \mathrm{~mL})$ until a yellow solution had formed. The solution was filtered and allowed to stand at room temperature overnight, during which time pale yellow crystals deposited. These were collected by filtration and washed with ethanol, then ether. Yield: $69 \mathrm{mg}(71 \%)$.

$\left[\mathrm{NH}_{4}\right]\left[\mathrm{NBu}_{4}\right]\left[\left(\mathrm{UO}_{2}\right)_{2}(\mathrm{c}-1,3-\mathrm{chdc})_{2}(t-1,3-c h d c)\right]$ (5). $c / t-1,3-\mathrm{chdcH}_{2}(17 \mathrm{mg}, 0.10 \mathrm{mmol})$, $\mathrm{UO}_{2}\left(\mathrm{NO}_{3}\right)_{2} \cdot 6 \mathrm{H}_{2} \mathrm{O}(35 \mathrm{mg}, 0.07 \mathrm{mmol})$, and $\mathrm{NBu} 4 \mathrm{Br}(33 \mathrm{mg}, 0.10 \mathrm{mmol})$ were dissolved in water $(0.4 \mathrm{~mL})$ and acetonitrile $(0.3 \mathrm{~mL})$. Yellow crystals of complex 5 were obtained in low yield within two months.

$\left[\mathrm{H}_{2} \mathrm{NMe}_{2}\right]_{2}\left[\left(\mathrm{UO}_{2}\right)_{2}(t-1,4-\mathrm{chdc})_{3}\right](6)$. A mixture of $\mathrm{rac}-\mathrm{t}-1,2-\mathrm{chdcH}_{2}(9 \mathrm{mg}, 0.05 \mathrm{mmol})$ and $t-1,4-\mathrm{chdcH}_{2}(9 \mathrm{mg}, 0.05 \mathrm{mmol})$, and $\mathrm{UO}_{2}\left(\mathrm{NO}_{3}\right)_{2} \cdot 6 \mathrm{H}_{2} \mathrm{O}(35 \mathrm{mg}, 0.07 \mathrm{mmol})$ were dissolved in 
water $(0.6 \mathrm{~mL})$ and DMF $(0.2 \mathrm{~mL})$. Yellow crystals of complex 6 were obtained in low yield within four days. The yield was not increased with longer reaction times.

Crystallography. The data were collected at 180(2) K (1 and 2) or 150(2) K (3-6) on a Nonius Kappa-CCD area detector diffractometer ${ }^{14}$ using graphite-monochromated Mo K $\alpha$ radiation $(\lambda=0.71073 \AA)$. The crystals were introduced into glass capillaries with a protective coating of Paratone-N oil (Hampton Research). The unit cell parameters were determined from ten frames, then refined on all data. The data (combinations of $\varphi$ - and $\omega$-scans with a minimum redundancy of 4 for $90 \%$ of the reflections) were processed with HKL2000. ${ }^{15}$ Absorption effects were corrected empirically with the program SCALEPACK. ${ }^{15}$ The structures were solved by intrinsic phasing with SHELXT, ${ }^{16}$ expanded by subsequent difference Fourier synthesis and refined by full-matrix least-squares on $F^{2}$ with SHELXL-2014. ${ }^{17}$ All non-hydrogen atoms were refined with anisotropic displacement parameters. The hydrogen atoms bound to oxygen and nitrogen atoms were retrieved from difference Fourier maps (except when indicated below), and the carbon-bound hydrogen atoms were introduced at calculated positions. All hydrogen atoms were treated as riding atoms with an isotropic displacement parameter equal to 1.2 times that of the parent atom (1.5 for $\mathrm{CH}_{3}$, with optimized geometry). Crystal data and structure refinement parameters are given in Table 1 . The molecular plots were drawn with ORTEP-3, ${ }^{18}$ and the polyhedral representations with VESTA. ${ }^{19}$ The topological analyses and nodal representations were made with ToposPro. ${ }^{20}$ Specific details are as follows.

Compound 1. The two solvent water molecules were given occupancy factors of 0.5 in order to retain acceptable displacement parameters and, in the case of $\mathrm{O} 11$, so as to allow for a short contact with its image by symmetry. The hydrogen atoms bound to O11 were not found. 
Compound 2. The hydrogen atoms of the water molecules of solvation were not found. 2component twinning was detected with TwinRotMat $\left(\mathrm{PLATON}^{21}\right)$ and taken into account during refinement.

Compound 5. Due to the low quality and weak diffracting power of the crystals, and also possibly to unresolved disorder in some parts of the structure, the refinement required the use of extensive restraints, particularly on displacement parameters, and also on several bond lengths and angles, both in the complex and the tetrabutylammonium counterion. The value of the refined Flack parameter indicates 2-component inversion twinning.

Compound 6. One dicarboxylate ligand is disordered around a binary axis, so that a complete ligand with half occupancy has been refined with restraints for some bond lengths and displacement parameters. The two dimethylammonium counter-ions are also disordered (with further disorder of the nitrogen atom over two positions in one of them), and they were refined with occupancy parameters of 0.5 and restraints on bond lengths, angles and displacement parameters.

Table 1. Crystal Data and Structure Refinement Details

\begin{tabular}{|c|c|c|c|c|c|c|}
\hline & 1 & 2 & 3 & 4 & 5 & 6 \\
\hline chemical formula & $\mathrm{C}_{8} \mathrm{H}_{16} \mathrm{O}_{9} \mathrm{U}$ & $\mathrm{C}_{80} \mathrm{H}_{86} \mathrm{O}_{25} \mathrm{P}_{2} \mathrm{U}_{3}$ & $\mathrm{C}_{8} \mathrm{H}_{12} \mathrm{O}_{7} \mathrm{U}$ & $\mathrm{C}_{10} \mathrm{H}_{18} \mathrm{O}_{8} \mathrm{U}$ & $\mathrm{C}_{40} \mathrm{H}_{70} \mathrm{~N}_{2} \mathrm{O}_{16} \mathrm{U}_{2}$ & $\mathrm{C}_{28} \mathrm{H}_{46} \mathrm{~N}_{2} \mathrm{O}_{16} \mathrm{U}_{2}$ \\
\hline$M\left(\mathrm{~g} \mathrm{~mol}^{-1}\right)$ & 494.24 & 2223.51 & 458.21 & 504.27 & 1311.04 & 1142.73 \\
\hline cryst syst & trigonal & triclinic & orthorhombic & monoclinic & orthorhombic & orthorhombic \\
\hline space group & $P 3_{1} 21$ & $P_{\overline{1}}$ & $P 2_{1} 2_{1} 2_{1}$ & $P 2_{1} / c$ & $\operatorname{Pna}_{1}$ & Fddd \\
\hline$a(\AA)$ & $10.9828(2)$ & $14.4451(8)$ & $6.6588(2)$ & $10.9088(6)$ & $33.3747(16)$ & $22.0743(6)$ \\
\hline$b(\AA)$ & $10.9828(2)$ & $15.0826(4)$ & $10.5235(7)$ & $11.4060(6)$ & $9.9163(6)$ & $23.1978(11)$ \\
\hline$c(\AA)$ & $18.5033(7)$ & $19.3850(10)$ & $15.9907(11)$ & $12.2961(5)$ & $14.2887(7)$ & $32.8456(19)$ \\
\hline$\alpha(\operatorname{deg})$ & 90 & $78.461(3)$ & 90 & 90 & 90 & 90 \\
\hline$\beta$ (deg) & 90 & $70.939(3)$ & 90 & $104.450(3)$ & 90 & 90 \\
\hline$\gamma(\operatorname{deg})$ & 120 & $80.382(3)$ & 90 & 90 & 90 & 90 \\
\hline$V\left(\AA^{3}\right)$ & $1932.89(12)$ & $3887.5(3)$ & $1120.53(11)$ & $1481.55(13)$ & $4728.9(4)$ & 16819.4(13) \\
\hline$Z$ & 6 & 2 & 4 & 4 & 4 & 16 \\
\hline reflns colled & 41565 & 208680 & 37119 & 43876 & 73217 & 81224 \\
\hline indep reflns & 2450 & 14786 & 3014 & 2811 & 8626 & 3991 \\
\hline obsd reflns $[I>2 \sigma(I)]$ & 2403 & 12167 & 2903 & 2360 & 5962 & 3095 \\
\hline$R_{\text {int }}$ & 0.034 & 0.063 & 0.021 & 0.029 & 0.038 & 0.020 \\
\hline params refined & 175 & 992 & 146 & 173 & 545 & 308 \\
\hline$R_{1}$ & 0.025 & 0.056 & 0.024 & 0.028 & 0.071 & 0.051 \\
\hline$w R_{2}$ & 0.064 & 0.131 & 0.056 & 0.066 & 0.194 & 0.156 \\
\hline$S$ & 1.080 & 1.097 & 1.077 & 1.041 & 1.022 & 1.048 \\
\hline$\Delta \rho_{\min }\left(\mathrm{e} \AA^{-3}\right)$ & -1.00 & -3.30 & -1.98 & -1.15 & -1.71 & -1.98 \\
\hline$\Delta \rho_{\max }\left(\mathrm{e} \AA^{-3}\right)$ & 0.58 & 3.51 & 0.80 & 1.09 & 1.24 & 2.43 \\
\hline Flack parameter & $0.012(18)$ & & $-0.006(16)$ & & $0.49(3)$ & \\
\hline
\end{tabular}




\section{RESULTS AND DISCUSSION}

Synthesis. As for all previously studied uranyl cyclohexanedicarboxylate complexes, ${ }^{6-12}$ complexes 1-3, $\mathbf{5}$ and $\mathbf{6}$ were synthesized under hydrothermal or solvo-hydrothermal conditions (the latter involving a mixture of water and organic solvent), and the crystals investigated were deposited at the temperature of $140{ }^{\circ} \mathrm{C}$. The organic cosolvents used were acetonitrile for complexes $\mathbf{2}$ and $\mathbf{5}$, and $N, N$-dimethylformamide (DMF) for $\mathbf{6}$, with as a consequence the presence of $\mathrm{NH}_{4}{ }^{+}$or $\mathrm{H}_{2} \mathrm{NMe}_{2}{ }^{+}$cations in $\mathbf{5}$ and $\mathbf{6}$, respectively, generated in situ from hydrolysis of the organic solvent. Complex 4 was obtained from an experiment designed to see if the tetranuclear $\left[\left(\mathrm{UO}_{2}\right)_{4}(t-1,2-\mathrm{chdc})_{6}\right]^{4-}$ anion ${ }^{7}$ might be isolable in association with $\mathrm{H}^{+}$; this complex crystallized from aqueous ethanol at room temperature after the initial reaction mixture had been briefly heated at $80{ }^{\circ} \mathrm{C}$ and this much lower crystallization temperature may have been the reason why the anticipated tetranuclear product was not obtained. So as to favour the formation of anionic uranyl complexes and thus allow incorporation of structure-directing counterions, the uranium/dicarboxylate ligand ratio was $7: 10$ for all the complexes obtained under (solvo-)hydrothermal conditions. However, the expected 2:3 ratio is only found for complexes 5 and 6, while complex $\mathbf{2}$ has a 3:4 ratio, and complexes $\mathbf{1}$ and $\mathbf{3}$ (as well as $\mathbf{4}$, also obtained from a reaction mixture with a 2:3 ratio) have a 1:1 ratio and are thus neutral. Whereas it was synthesized from pure $c$-1,2-chdcH $\mathrm{H}_{2}$, complex 2 contains a mixture of the $c i s$ and trans forms, indicating partial transformation of the cis into the trans form under the conditions used. This was not observed in any of our previous experiments with this ligand, ${ }^{8,11,12}$ but we have observed racemization of the trans isomer, ${ }^{12}$ a process which must pass through the cis isomer as an intermediate and both this and the present observations are consistent with the cis/trans equilibrium lying strongly in favour 
of the latter under solvothermal conditions. Facile inversion of $>\mathrm{CHCO}_{2} \mathrm{H}$ centres has also been observed during the formation of uranyl ion complexes of cis,trans,cis-1,2,3,4cyclobutanetetracarboxylic acid, leading to the presence of the trans,trans,trans form. ${ }^{22}$ These inversion processes presumably involve partial 2-CH dissociation of the bound carboxylate ligand to give a readily inverting carbanion or acid-catalyzed rearrangement to an achiral ene-diol intermediate. As seen, for example, in the case of complex 1, the isolated product did not necessarily contain all the species added to the original reaction mixture with a particular target product in mind, perhaps an unsurprising result but one illustrative of the capriciousness of solvothermal syntheses.

Crystal Structures. The complex $\left[\mathrm{UO}_{2}(c-1,2-c h d c)\left(\mathrm{H}_{2} \mathrm{O}\right)_{2}\right] \cdot \mathrm{H}_{2} \mathrm{O}(\mathbf{1})$ crystallizes in the trigonal chiral space group $P 3_{1} 21$, and the two independent uranium atoms are located on twofold rotation axes (Wyckoff positions $3 b$ and $3 a$ for $\mathrm{U} 1$ and $\mathrm{U} 2$, respectively). Both are chelated in $\kappa^{2} O, O^{\prime}$ mode by one carboxylate group of the unique $c-1,2-\operatorname{chdc}^{2-}$ ligand and its image by symmetry (Figure 1). Two water molecules are also coordinated to each uranyl ion, the uranium environment being thus hexagonal bipyramidal [U-O(oxo) 1.769(7) $\AA$, U-O(carboxylato) $2.379(10)-2.558(7) \AA]$. The two carboxylate groups, as well as the two water molecules, are trans in the case of U1 (with the water molecules located on the twofold rotation axis) and cis in the case of U2. The two carboxylate groups of the $c-1,2-\operatorname{chdc}^{2-}$ ligand (in the chair conformation) are in the axial and equatorial positions (ae form), as usual. ${ }^{8,11,12}$ A 1D helical polymer running parallel to [001] is formed, which is centered on the threefold screw axis, the screw thread being thus equal to the $c$ axis unit length, $18.5 \AA$. Viewed down this axis, the chain displays a central column of slightly inclined uranyl cations (U2), and three lateral rows of strongly tilted uranyl cations (U1), 

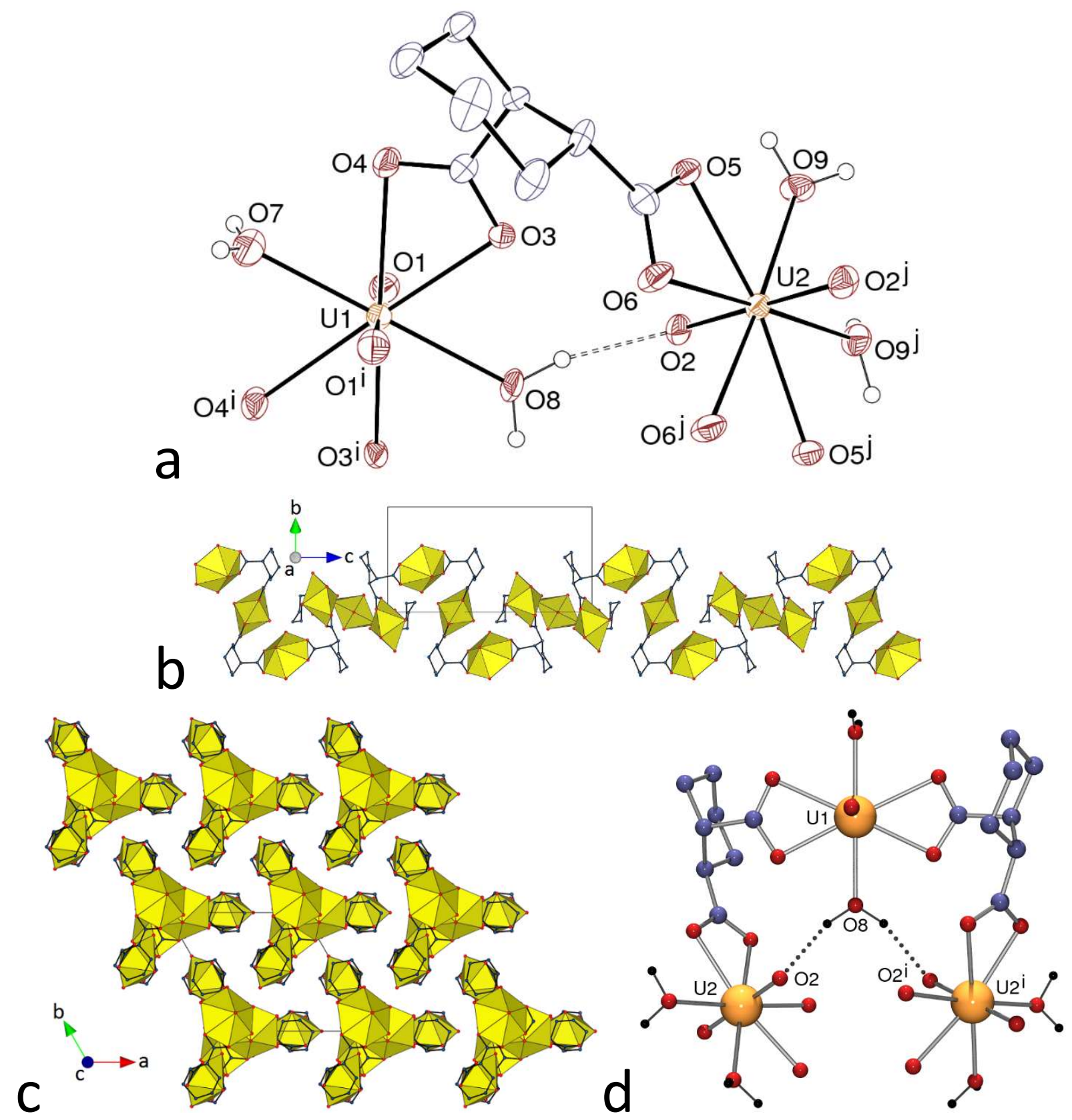

Figure 1. (a) View of compound 1. Displacement ellipsoids are drawn at the $40 \%$ probability level. Carbon-bound hydrogen atoms and solvent molecule are omitted, and the hydrogen bond is shown as a dashed line. Symmetry codes: $\mathrm{i}=y, x, 1-z ; \mathrm{j}=2-x, y-x+1,4 / 3-z$. (b) View of the $1 \mathrm{D}$ helical polymer. (c) Packing with chains viewed end-on. Uranium coordination polyhedra are colored yellow. (d) Intrachain hydrogen bonding (dotted lines). 
and as consequence the helix does not define a tubular geometry, but has a triangular section. The value of the refined Flack parameter [0.012(18)] indicates that the crystal is enantiomerically pure, one chiral configuration of the ligand being associated with a particular helix handedness (righthanded in the particular crystal chosen, with the axially disposed carboxylate on the carbon of $R$ configuration). The complexed water molecules are involved in intra- and interchain hydrogen bonding $\left[\mathrm{O} \cdots \mathrm{O} 2.628(9)-2.943(9) \AA, \mathrm{O}-\mathrm{H} \cdots \mathrm{O} 117-158^{\circ}\right]$, and the free water molecules provide further links between chains. Most interesting are the hydrogen bonds involving the water ligand including $\mathrm{O} 8$ as a donor and the uranyl oxo atom $\mathrm{O} 2$ as an acceptor: these two bonds, related by the twofold rotation axis, subtend the curved $\mathrm{U} 2-\mathrm{L}-\mathrm{U} 1-\mathrm{L}^{\mathrm{i}}-\mathrm{U} 2^{\mathrm{i}}$ subunit $\left(\mathrm{L}=c-1,2-\mathrm{chdc}^{2-}\right)$, as shown in Figure 1d. These quasi-planar motifs, which constitute the lateral blades of the chains, are bound to one another through the cis-connection around atom $\mathrm{U} 2$ which provides the rotation generating the helix. $c-1,2-\operatorname{chdc}^{2-}$ is a ligand which, in solution, behaves as an achiral species due to its rapid inversion between enantiomeric ae conformations; it is known that a single enantiomer can be isolated in the crystalline state, ${ }^{23}$ but this prior example involves a salt of the acid formed with a chiral cation. It is not obvious why the presence of a particular enantiomer in one site in complex 1 should lead to all other sites being occupied by the same enantiomer but, as is evident from the view of the lattice down [001] (Fig. 1c), cyclohexyl rings of one helix project into hollows of adjacent helices in such a way as to lead to close $\mathrm{CH} \cdots \mathrm{O}$ approaches, which may help propagate the chirality of one chain to its neighbours. The helical chains are tightly packed, and the Kitaigorodski packing index (KPI), calculated with PLATON,${ }^{21}$ is 0.66 (with solvent excluded). Partial transformation of $c-1,2-\operatorname{chdc}^{2-}$ into $t-1,2-\operatorname{chdc}^{2-}$ (see above) gives the mixed-ligand complex $\left[\mathrm{PPh}_{4}\right]_{2}\left[\left(\mathrm{UO}_{2}\right)_{3}(c-1,2-\mathrm{chdc})_{3}(\right.$ rac-t-1,2-chdc $\left.)\left(\mathrm{H}_{2} \mathrm{O}\right)\right] \cdot 2 \mathrm{H}_{2} \mathrm{O}$ (2). Two of the three independent uranium atoms (U1 and U3) are chelated by three carboxylate groups and are in 
hexagonal bipyramidal environments, while the third (U2), chelated by one carboxylate and bound to two more carboxylate oxygen donors and one water molecule, is in a pentagonal bipyramidal environment (Figure 2) [U-O(oxo) 1.733(7)-1.776(8) Å, U-O(chelating carboxylato) 2.426(9)2.491(7) Å, U-O(bridging carboxylato) 2.300(6) and 2.392(6) $\AA$ ]. The three $c$-1,2-chdc ${ }^{2-}$ ligands, are in the usual chair, ae conformation, while the single $t-1,2-\operatorname{chdc}^{2-}$ ligand, also in the chair form, has its two carboxylate groups axial ( $a a)$, a conformation which has previously been encountered in other uranyl ion complexes, ${ }^{10,12}$ although the most usual conformation is diequatorial (ee); in contrast to the convergent $e e$ form, the $a a$ one is divergent. The trans and two of the cis ligands are bis-chelating (bis $\left(\kappa^{2} O, O^{\prime}\right)$ mode) and thus simple links, whereas the third cis ligand has one carboxylate group chelating and the other bridging bidentate $\left(\mu_{2}-\kappa^{1} O: \kappa^{1} O^{\prime}\right)$ and is thus a threefold node. The versatility of the carboxylate group as a ligand for uranyl ion is very well $\mathrm{known}^{3}$ and the presence of two very common modes of binding in the structure of complex $\mathbf{2}$ would suggest that bridging is favoured for the cis over the trans isomer. However, the binding modes are certainly influenced by the nature of the counter cation, here $\mathrm{PPh}_{4}{ }^{+}$, to the anionic polymer. When this countercation is $[\mathrm{Ni}(\mathrm{cyclam})]^{2+}$, for example, ${ }^{12}$ both ligands can adopt bridging modes and in fact appear to favour bridging-chelation, particularly when uranyl and nickel(II) are the bridged centres. $\mathrm{PPh}_{4}{ }^{+}$, of course, does not act as a Lewis acid by coordination as does $\mathrm{Ni}^{\mathrm{II}}$ but it is involved in multiple $\mathrm{CH} \cdots \mathrm{O}$ interactions with the carboxylate groups. The coordination polymer formed in 2 is $1 \mathrm{D}$ and parallel to [010], and it has a somewhat ladderlike shape. The chains can be viewed as built from a succession of centrosymmetric hexanuclear subunits, themselves containing two trinuclear groups linked to one another by the bridging bidentate carboxylate groups (Figure 2c). Each 1D polymer chain thus contains both enantiomers of both the ae cis isomer and the aa trans. 

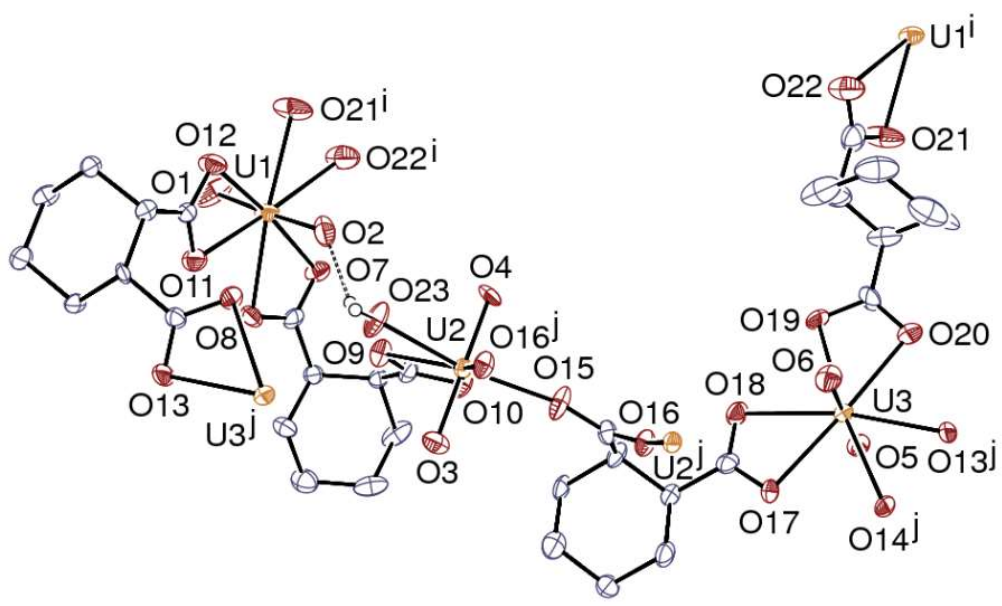

a
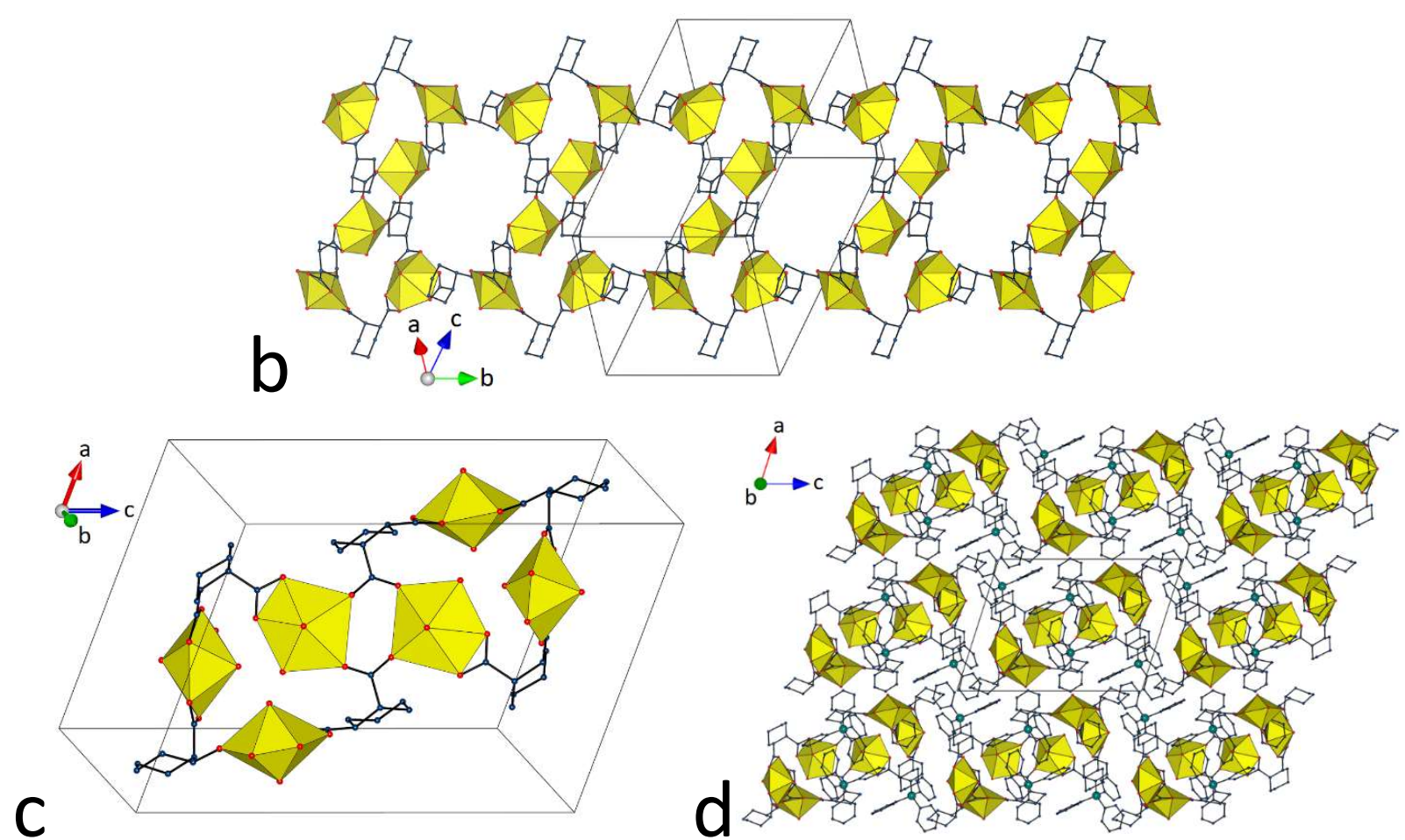

Figure 2. (a) View of compound 2. Displacement ellipsoids are drawn at the $40 \%$ probability level. Carbon-bound hydrogen atoms, counterions and solvent molecules are omitted, and the hydrogen bond is shown as a dashed line. Symmetry codes: $\mathrm{i}=1-x, 2-y, 1-z ; \mathrm{j}=1-x, 1-y, 1-z$. (b) View of the $1 \mathrm{D}$ polymer. (c) View of the hexanuclear subunit. (d) Packing with chains viewed end-on; channels run obliquely, parallel to [101].

The packing displays channels parallel to [101] centered on the rings apparent in the chains and containing columns of $\mathrm{PPh}_{4}^{+}$counterions. Within these columns, the counterions are associated in 
twos through interactions of the 'sextuple phenyl embrace' type, ${ }^{24}$ with P...P distances of 6.833(5) $\AA$ for $\mathrm{P} 1$ and $6.410(5) \AA$ for $\mathrm{P} 2$ and they are also involved, as stated above, in $\mathrm{CH} \cdots \mathrm{O}$ interactions with the anionic polymer. With a KPI of 0.69 , the packing does not contain significant free space.

The complex $\left[\mathrm{UO}_{2}(R-t-1,2-\mathrm{chdc})\left(\mathrm{H}_{2} \mathrm{O}\right)\right](3)$, with the pure $(1 R, 2 R)$ enantiomer of the ligand, crystallizes in the orthorhombic Sohncke space group $P 2{ }_{1} 2{ }_{1}{ }_{1}$, with a unique uranyl cation bound to one chelating carboxylate group, two more carboxylate donors and a water molecule, the uranium environment being pentagonal bipyramidal (Figure 3) [U-O(oxo) 1.766(5) $\AA$, U$\mathrm{O}$ (chelating carboxylato) 2.461(5) $\AA$, U-O(bridging carboxylato) $2.313(5)$ and $2.347(5) \AA]$. The $R-t-1,2-\operatorname{chdc}^{2-}$ ligand is in the ee chair conformation, and is a threefold node, as is the uranium centre, in the $2 \mathrm{D}$ assembly formed. A further illustration of the subtlety of factors influencing the 1,2-chdc ${ }^{2-}$ binding modes is the fact that here and in contrast with complex $\mathbf{2}$, it is the trans isomer which is found exclusively in the $\kappa^{2} O, O^{\prime}$ plus $\mu_{2}-\kappa^{1} O ; \kappa^{1} O^{\prime}$ mode. The network is parallel to (001), and it has the point (Schläfli) symbol $\left\{6^{3}\right\}$ and the hcb (honeycomb) topological type. The cyclohexyl rings point alternately on either side, the packing being of the bump-to-hollow type (KPI 0.70). The water ligand is involved in two intralayer hydrogen bonds with the carboxylate oxygen atoms $\mathrm{O} 3$ and $\mathrm{O} 4\left[\mathrm{O} \cdots \mathrm{O} 2.797(7)\right.$ and 2.680(7) $\AA$, $\mathrm{O}-\mathrm{H} \cdots \mathrm{O} 159$ and $150^{\circ}$, respectively], these bonds spanning the small hexanodal rings. The nature of complex $\mathbf{3}$ is illustrative of the effects of solvent composition in that from pure water here, the hydrate was deposited, whereas previous study ${ }^{6}$ of the complex using aqueous acetronitrile provided the anhydrous species. 

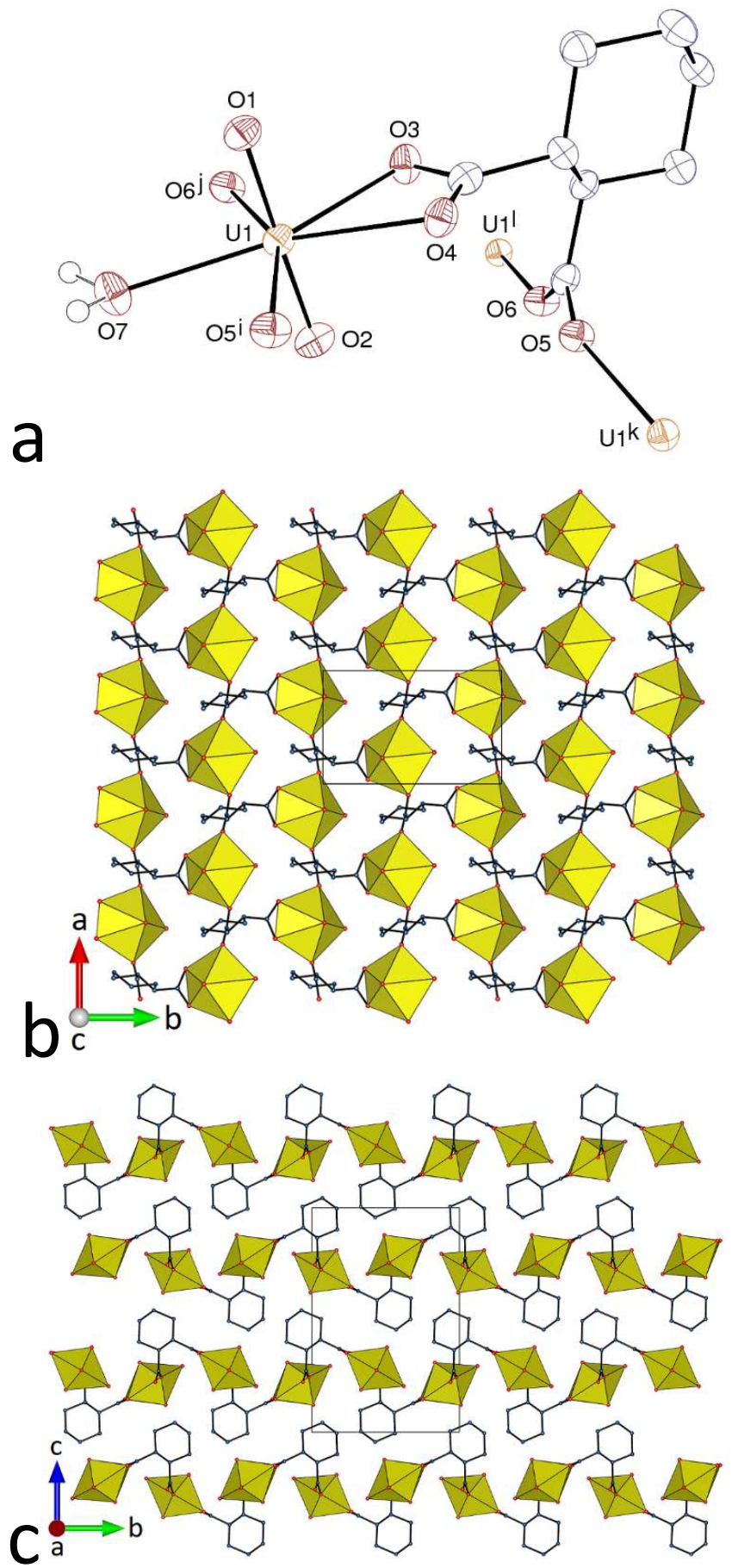

Figure 3. (a) View of compound 3. Displacement ellipsoids are drawn at the $50 \%$ probability level. Carbon-bound hydrogen atoms are omitted. Symmetry codes: $\mathrm{i}=1-x, y-1 / 2,3 / 2-z ; \mathrm{j}=-x, y-1 / 2,3 / 2-z ; \mathrm{k}=1-x, y+1 / 2,3 / 2$ $-z ; 1=-x, y+1 / 2,3 / 2-z$. (b) View of the 2D honeycomb-type assembly. (c) Packing with layers viewed edge-on. 
The complex $\left[\mathrm{UO}_{2}(\right.$ rac-t-1,2-chdc $\left.)(\mathrm{EtOH})\right] \cdot \mathrm{H}_{2} \mathrm{O}$ (4) is the only one among all those involving this family of ligands to have been crystallized at room temperature. Somewhat paradoxically, given the evidence that classical hydrogen bonding may have upon the structure of uranyl carboxylate complexes, ${ }^{12}$ this complex involving the hydrogen bond donor ethanol ligand is isomorphous to other, solvo-hydrothermally synthesized complexes containing exclusively hydrogen bond acceptor ligands, $\left[\mathrm{UO}_{2}(\right.$ rac-t-1,2-chdc $\left.)(\mathrm{L})\right]$, with $\mathrm{L}=\mathrm{THF}$, DMF or NMP $(N-$ methyl-2-pyrrolidone), ${ }^{6}$ and it is also very close to $\left[\mathrm{UO}_{2}(c-1,2-\mathrm{chdc})(\mathrm{DMF})\right]^{8}$ and $\left[\mathrm{UO}_{2}(c-1,4-\right.$ chdc)(DMF)]. ${ }^{9}$ The bonding mode of the dicarboxylate ligand, in the ee chair conformation, is the same as that found in complex $\mathbf{3}$, but, in the pentagonal equatorial environment of the uranyl ion [U-O(oxo) 1.758(4) and 1.751(4) $\AA, \mathrm{U}-\mathrm{O}$ (chelating carboxylato) 2.470(3) and 2.490(4) $\AA$, UO(bridging carboxylato) 2.280(4) and 2.357(4) $\AA$, U-O(ethanolato) 2.409(4) $\AA$ ], the two oxygen atoms from the bridging bidentate groups are located side-by-side (Figure 4), whereas they are separated by the water molecule in 3 . The $2 \mathrm{D}$ assembly formed, parallel to (100) has the point symbol $\left\{4.8^{2}\right\}$ and the fes topological type. The layers are corrugated, with the cyclohexyl rings pointing on either side, and the packing is compact (KPI 0.66). Both enantiomers of the ligand are present in any given layer (the pairs of carboxylato-bridged uranium atoms being centrosymmetric). The hydrogen bonds formed by the ethanol and free water molecule are intralayer and they span the centrosymmetric octanodal rings, in which the water molecules are located (Figure 4e) $\left[\mathrm{O} \cdots \mathrm{O} 2.601(6)-2.815(6) \AA\right.$, $\left.\mathrm{O}-\mathrm{H} \cdots \mathrm{O} \quad 140-170^{\circ}\right]$. The central hydrogen bonding ring has the graph set descriptor ${ }^{25,26} R_{4}^{4}(12)$, while the lateral rings correspond to $R_{2}^{2}(11)$. As in complex 1, hydrogen bonding may have here some structure-directing effect. 

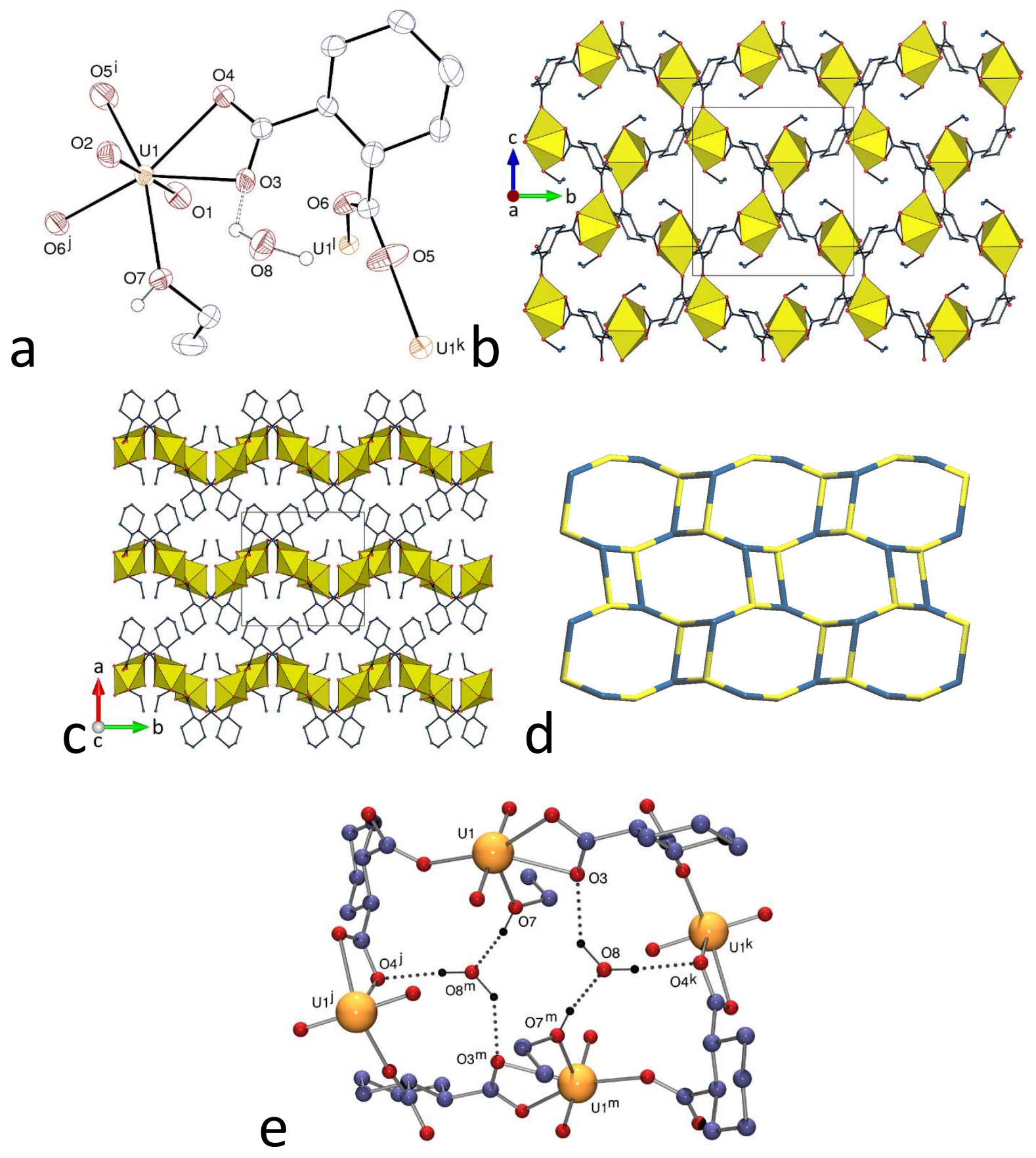

Figure 4. (a) View of compound 4. Displacement ellipsoids are drawn at the $40 \%$ probability level. Carbon-bound hydrogen atoms are omitted. Symmetry codes: $\mathrm{i}=x, 1 / 2-y, z+1 / 2 ; \mathrm{j}=1-x, y-1 / 2,3 / 2-z ; \mathrm{k}=x, 1 / 2-y, z-1 / 2 ; 1$ $=1-x, y+1 / 2,3 / 2-z$. (b) View of the 2D assembly. (c) Packing with layers viewed edge-on. (d) Nodal representation of the 2D network (uranium, yellow; dicarboxylate ligand, dark blue; same orientation as in b. (e) Hydrogen bonding pattern; symmetry codes: as for a, and $\mathrm{m}=1-x,-y, 1-z$. 
The complex $\left[\mathrm{NH}_{4}\right]\left[\mathrm{NBu}_{4}\right]\left[\left(\mathrm{UO}_{2}\right)_{2}(c-1,3-\mathrm{chdc})_{2}(t-1,3-\mathrm{chdc})\right](5)$, shown in Figure 5, contains both the cis and trans isomers of 1,3-chdc ${ }^{2-}$, in agreement with the use of a mixture of the acids, as in one of the other three uranyl ion complexes with $1,3-$ chdc $^{2-}$ previously described, ${ }^{27}$ whereas the cis isomer only was found in the other two cases. ${ }^{11,27}$ Each of the two independent uranyl cations in $\mathbf{5}$ is chelated by three carboxylate groups [U-O(oxo) 1.748(18)-1.82(2) $\AA$, U$\mathrm{O}$ (carboxylato) 2.38(2)-2.509(19) $\AA]$. All the ligands are in the chair conformation, the cis isomers being ee and the trans ae. The assembly formed is 3D and it has the point symbol $\left\{10^{2} .12\right\}\left\{10^{3}\right\}$. Channels with an irregularly shaped section and approximately $8 \AA$ wide run along [010], in which the $\mathrm{NBu}_{4}^{+}$cations are located; the KPI with counterions excluded is 0.42 only $(0.67$ with counterions). The $\mathrm{NH}_{4}^{+}$cation has a distinctive role as a hydrogen bond donor, since it is located in the curved part defined by the $\left(\mathrm{UO}_{2}\right)_{2}(t-1,3-\mathrm{chdc})^{2+}$ subunit, which, with the two attached $c-1,3-$ chdc $^{2-}$ ligands, makes what could be described as a partial metallacycle, as shown in Figure 5a. The ammonium cation is involved in three hydrogen bonds (one of them bifurcated) with the carboxylate groups lining the cavity, thus defining $R_{1}^{2}(4), R_{2}^{2}(10)$ and $R_{2}^{2}(6)$ rings, the fourth proton being bound to another carboxylate oxygen atom $[\mathrm{N} \cdots \mathrm{O} 2.85(3)-3.06(3) \AA, \mathrm{N}-\mathrm{H} \cdots \mathrm{O} 133-$ $161^{\circ}$ ]. As in several other cases of uranyl ion complexes containing $\mathrm{NH}_{4}{ }^{+}$cations, the structuredirecting ability of the latter, through multiple hydrogen bonding involving acceptors close to each other, seem at play here. These effects may form curved, open motifs as in $\mathbf{5}$, and also promote the formation of fully closed molecular species as observed with $c-1,2-\operatorname{chdc}^{2-}, 8$ tricarballylate, ${ }^{28}$ and 1,3-adamantanediacetate. ${ }^{29}$ 

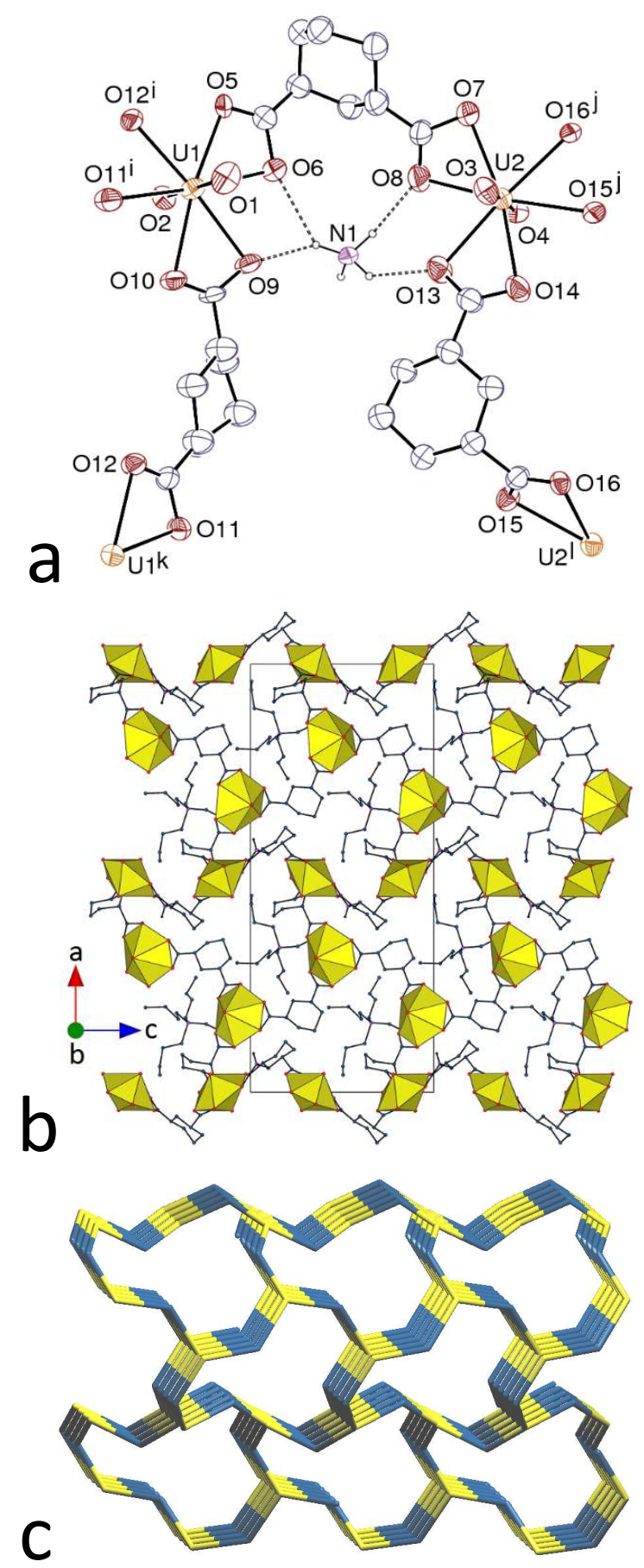

Figure 5. (a) View of compound 5. Displacement ellipsoids are drawn at the $20 \%$ probability level. Carbon-bound hydrogen atoms and $\mathrm{NBu}_{4}{ }^{+}$cations are omitted, and hydrogen bonds are shown as dashed lines. Symmetry codes: $\mathrm{i}=$ $3 / 2-x, y+1 / 2, z-1 / 2 ; \mathrm{j}=1-x,-y-1, z-1 / 2 ; \mathrm{k}=3 / 2-x, y-1 / 2, z+1 / 2 ; 1=1-x,-y-1, z+1 / 2$. (b) View of the 3D framework. (c) Nodal representation of the framework (uranium, yellow; dicarboxylate ligand, dark blue; orientation slightly rotated with respect to that in b. 
The complex $\left[\mathrm{H}_{2} \mathrm{NMe}_{2}\right]_{2}\left[\left(\mathrm{UO}_{2}\right)_{2}(t-1,4-\mathrm{chdc})_{3}\right](\mathbf{6})$ is different from the other complexes with the cis and/or trans isomers of 1,4-chdc ${ }^{2-}$ including $\mathrm{H}_{2} \mathrm{NMe}_{2}{ }^{+}$cations already known. ${ }^{9}$ This complex crystallizes in the orthorhombic space group $F d d d$, and the unique uranium atom, in general position, is here also chelated by three carboxylate groups (Figure 6) [U-O(oxo) 1.761(8) and 1.756(8) $\AA, \mathrm{U}-\mathrm{O}$ (carboxylato) $2.32(3)-2.481(7) \AA]$. One of the ligands (O3 to O6) is in the ee chair conformation, but the other $(\mathrm{O} 7$ to $\mathrm{O} 10)$ is disordered and, although it is most probably in the same ee chair conformation, the presence of the ee boat form of the cis isomer cannot definitely be excluded. The polymeric assembly formed is $3 \mathrm{D}$, and it has the point symbol $\left\{10^{3}\right\}$ and the topological type ths (Figure 6d). The same topological type was found in the complex $\left[\mathrm{Cu}(\text { bipy })_{2}\right]_{2}\left[\left(\mathrm{UO}_{2}\right)_{2}(c-1,4-\mathrm{chdc})_{2}(t-1,4-\mathrm{chdc})\right] \cdot 2 \mathrm{H}_{2} \mathrm{O},{ }^{9}$ and also in a uranyl ion complex with the tripodal ligand $4,4^{\prime}, 4^{\prime \prime}$-(phenylsilanetriyl)tribenzoate. ${ }^{30}$ What is remarkable in the present case is that, while the last two compounds display twofold interpenetration, complex $\mathbf{6}$ is an example of class IIIa sixfold interpenetration (Figure 6e), with $[1 / 2,1 / 2,0]$ and $[1 / 2,-1 / 2,0]$ as translational interpenetrating vectors (TIV) and inversion as non-translational interpenetrating symmetry element (NISE). ${ }^{31}$ It is notable that the ths topology is one of the most frequently found in interpenetrating nets, and that the interpenetration degree of 6 , although much less frequent than the smaller degrees (particularly 2 and 3) still represents a small but appreciable proportion of all interpenetrated nets ${ }^{32}$ (much larger degrees are possible, as shown by the report of a 54 -fold interpenetrated net, with the related $\left\{10^{3}\right\}$ srs topology ${ }^{33}$ ). Interpenetration, ${ }^{34,35}$ as well as other entanglements such as polycatenation, ${ }^{36}$ in uranyl-containing compounds is now relatively common, ${ }^{9,30,37-42}$ but, to the best of our knowledge, such a large degree of interpenetration as found in 6 has not been reported up to know, the degree being at most 3 in previous cases. The twofold 


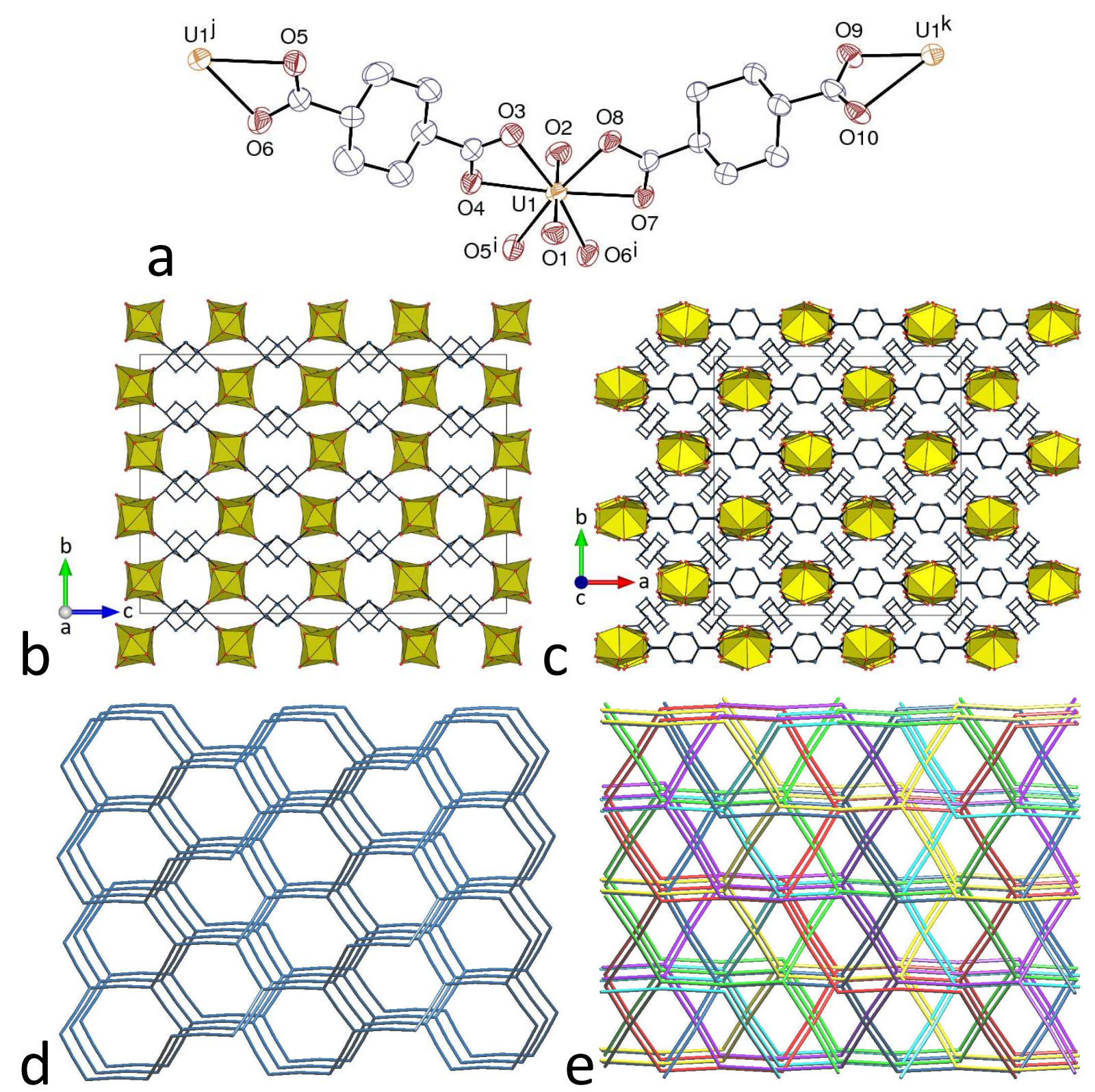

Figure 6. (a) View of compound 6. Displacement ellipsoids are drawn at the $30 \%$ probability level. Hydrogen atoms and counterions are omitted. Only one position of the disordered atoms is represented. Symmetry codes: $\mathrm{i}=3 / 2-x, y$ $-1 / 4, z+1 / 4 ; \mathrm{j}=3 / 2-x, y+1 / 4, z-1 / 4 ; \mathrm{k}=3 / 4-x, 3 / 4-y, z$. (b) and (c) Two views of the 3D entangled framework. (d) Nodal representation of a single 3D assembly viewed down [010], with [100] horizontal. (e) Nodal representation of the sixfold interpenetrated net; same orientation as in $d$, but different scale. 
interpenetrated complex with $1,4-\mathrm{chdc}^{2-}$ and $\left[\mathrm{Cu}(\text { bipy })_{2}\right]^{+}$counterions displays large channels occupied by the bulky cations, while the presence of smaller $\mathrm{H}_{2} \mathrm{NMe}_{2}{ }^{+}$counterions in 6 leaves more space available for further entanglement. It is also notable that, while all the other interpenetrated assemblies involving 1,4-chdc ${ }^{2-}$ contain a mixture of the cis and trans isomers, 6 contains most probably (see above) only the more elongated trans ee form. The disordered $\mathrm{H}_{2} \mathrm{NMe}_{2}{ }^{+}$counterions provide hydrogen bonding links between entangled nets and, although no reliable KPI can be calculated due to the presence of very disordered groups (see Experimental Section), the packing does not display significant porosity. The intriguing question of how such an interpenetrated lattice might form cannot be answered simply on the basis of the structure found but the fact that hydrogen bonding to the $\mathrm{H}_{2} \mathrm{NMe}_{2}{ }^{+}$counterions links the sixfold interpenetrated array of 3D polymers into a single higher array implies that crystallisation may be initiated by large polyion aggregates.

\section{CONCLUSIONS}

Although but a small family within the extensive range of polycarboxylate ligands, the isomers of cyclohexanedicarboxylates have provided uranyl ion complexes which, in the crystalline state, display a remarkable diversity of structure. ${ }^{6-12,27}$ All the complexes obtained up to now with the different isomers and enantiomers of 1,2-chdc ${ }^{2-}$ are listed in Table 2, which includes the chirality of the ligands used for the synthesis, the nature (centrosymmetric, chiral or otherwise) of the space group, the chirality of the final compound, the orientation, axial or equatorial, of the carboxylate groups and the periodicity of the structure. Table 3 lists all the complexes obtained with 1,3- and 1,4-chdc ${ }^{2-}$, with the orientation of the carboxylate groups, periodicity and, when applicable, interpenetration degree. In addition, the coordination modes found in the whole series of complexes are shown in Scheme 1. Our first comment concerns the number of complexes obtained with the different isomers. While approximately equal numbers of experiments have been performed with 
Table 2. Uranyl Ion Complexes with $c$ - and $t-1,2-\operatorname{chdc}^{2-}$

\begin{tabular}{|c|c|c|c|c|c|c|}
\hline compound $^{a}$ & $\begin{array}{l}\text { ligand original } \\
\text { chirality }\end{array}$ & space group & compound chirality & $\begin{array}{l}\text { substituents } \\
\text { orientation }^{b}\end{array}$ & periodicity & ref \\
\hline \multicolumn{7}{|l|}{ cis isomer } \\
\hline$\left[\mathrm{UO}_{2}(c-1,2-\mathrm{chdc})\left(\mathrm{H}_{2} \mathrm{O}\right)_{2}\right]$ & racemic & chiral & enantiopure & ae & 1 & this work \\
\hline$\left[\mathrm{UO}_{2}(c-1,2-\mathrm{chdc})(\mathrm{DMF})\right]$ & racemic & centrosymmetric & racemic & ae & 2 & 8 \\
\hline$\left[\mathrm{UO}_{2}(c-1,2-\mathrm{chdc})\left(\mathrm{H}_{2} \mathrm{O}\right)\right]$ & racemic & centrosymmetric & racemic & ae & 2 & 8 \\
\hline$\left[\left(\mathrm{UO}_{2}\right)_{4} \mathrm{Na}_{2}(c-1,2-\mathrm{chdc})_{2}\left(\mathrm{C}_{2} \mathrm{O}_{4}\right)_{3}(15 \mathrm{C} 5)_{2}\right]$ & racemic & centrosymmetric & racemic & $a e$ & 2 & 11 \\
\hline$\left[\left(\mathrm{UO}_{2}\right)_{4} \mathrm{~K}_{2}(c-1,2 \text {-chdc })_{2}\left(\mathrm{C}_{2} \mathrm{O}_{4}\right)_{3}(18 \mathrm{C} 6)_{1.5}\left(\mathrm{H}_{2} \mathrm{O}\right)_{1.5}\right]$ & racemic & centrosymmetric & racemic & $a e$ & 2 & 11 \\
\hline$\left[\mathrm{UO}_{2}(c-1,2-\text { chdc })_{2} \mathrm{Ni}(\right.$ cyclam $\left.)\left(\mathrm{H}_{2} \mathrm{O}\right)\right]$ & racemic & centrosymmetric & racemic & $a e$ & 2 & 12 \\
\hline$\left[\left(\mathrm{UO}_{2}\right)_{2}(c-1,2 \text {-chdc })_{2}(c \text {-chdcH })_{2} \mathrm{Ni}(\right.$ cyclam $\left.)\right]$ & racemic & centrosymmetric & racemic & ae & 2 & 12 \\
\hline$\left[\mathrm{NH}_{4}\right]\left[\mathrm{PPh}_{4}\right]\left[\left(\mathrm{UO}_{2}\right)_{8}(c-1,2 \text {-chdc })_{9}\left(\mathrm{H}_{2} \mathrm{O}\right)_{6}\right]$ & racemic & non-centrosymmetric & racemic & ae & 0 & 8 \\
\hline$\left[\mathrm{PPh}_{4}\right]_{2}\left[\left(\mathrm{UO}_{2}\right)_{3}(c-1,2-\mathrm{chdc})_{3}(t-1,2-\mathrm{chdc})\left(\mathrm{H}_{2} \mathrm{O}\right)\right]$ & racemic & centrosymmetric & racemic (isomerized) & $a e(c) a a(t)$ & 1 & this work \\
\hline \multicolumn{7}{|l|}{ trans isomer } \\
\hline$\left[\mathrm{UO}_{2}(R-t-1,2-\mathrm{chdc})\right]$ & $(1 R, 2 R)$ enantiomer & Sohncke & enantiopure & $e e$ & 2 & 6 \\
\hline$\left[\mathrm{UO}_{2}(R-t-1,2-\mathrm{chdc})\left(\mathrm{H}_{2} \mathrm{O}\right)\right]$ & $(1 R, 2 R)$ enantiomer & Sohncke & enantiopure & $e e$ & 2 & this work \\
\hline$\left[\mathrm{UO}_{2}(t-1,2-\mathrm{chdc})(\mathrm{EtOH})\right]$ & racemic & centrosymmetric & racemic & $e e$ & 2 & this work \\
\hline$\left[\mathrm{UO}_{2}(t-1,2-\mathrm{chdc})(\mathrm{THF})\right]$ & racemic & centrosymmetric & racemic & $e e$ & 2 & 6 \\
\hline$\left[\mathrm{UO}_{2}(t-1,2\right.$-chdc)(DMF) $]$ & racemic & centrosymmetric & racemic & $e e$ & 2 & 6 \\
\hline$\left[\mathrm{UO}_{2}(t-1,2-\mathrm{chdc})(\mathrm{NMP})\right]$ & racemic & centrosymmetric & racemic & $e e$ & 2 & 6 \\
\hline$\left[\mathrm{UO}_{2}(t-1,2-\mathrm{chdc})(\mathrm{bipy})\right]$ & racemic & chiral & racemic conglomerate & $e e$ & 1 & 6 \\
\hline$\left[\mathrm{UO}_{2}(R-t-1,2-\mathrm{chdc})(\mathrm{bipy})\right]$ & $(1 R, 2 R)$ enantiomer & chiral & enantiopure & $e e$ & 1 & 6 \\
\hline$\left[\mathrm{UO}_{2} \mathrm{Cu}(t-1,2-\mathrm{chdc})_{2}(\right.$ bipy $\left.)\left(\mathrm{H}_{2} \mathrm{O}\right)\right]$ & racemic & centrosymmetric & racemic & $e e$ & 1 & 6 \\
\hline$\left[\mathrm{UO}_{2} \mathrm{Cu}(R-t-1,2 \text {-chdc })_{2}\right.$ (bipy) $]$ & $(1 R, 2 R)$ enantiomer & Sohncke & enantiopure & $e e$ & 2 & 6 \\
\hline$\left[\mathrm{UO}_{2} \mathrm{Cd}(R-t-1,2-\mathrm{chdc})_{2}\left(\mathrm{H}_{2} \mathrm{O}\right)_{2}\right]$ & $(1 R, 2 R)$ enantiomer & Sohncke & enantiopure & $e e$ & 2 & 6 \\
\hline$\left[\mathrm{NH}_{4}\right]_{4}\left[\left(\mathrm{UO}_{2}\right)_{4}(t-1,2-\mathrm{chdc})_{6}\right]$ & racemic & centrosymmetric & racemic & $e e$ & 0 & 7 \\
\hline$\left[\left(\mathrm{UO}_{2}\right)_{2} \mathrm{Na}_{2}(t-1,2-\mathrm{chdc})_{3}\left(\mathrm{H}_{2} \mathrm{O}\right)_{2}\right]$ & racemic & centrosymmetric & racemic & $e e$ & $0 / 3^{c}$ & 6 \\
\hline$\left[\left(\mathrm{UO}_{2}\right)_{2} \mathrm{Na}_{2}(R-t-1,2-\mathrm{chdc})_{3}\left(\mathrm{H}_{2} \mathrm{O}\right)_{2}\right]$ & $(1 R, 2 R)$ enantiomer & Sohncke & enantiopure & $e e$ & $0 / 3$ & 6 \\
\hline$\left[\left(\mathrm{UO}_{2}\right)_{4} \mathrm{~K}_{4}(R-t-1,2-\mathrm{chdc})_{6}\left(\mathrm{H}_{2} \mathrm{O}\right)_{6}\right]$ & $(1 R, 2 R)$ enantiomer & Sohncke & enantiopure & $e e$ & $0 / 3$ & 7 \\
\hline$\left[\mathrm{H}_{2} \mathrm{NMe}_{2}\right]\left[\left(\mathrm{UO}_{2}\right)_{4} \mathrm{Rb}_{3}(R-t-1,2-\mathrm{chdc})_{6}\left(\mathrm{H}_{2} \mathrm{O}\right)_{1.75}\right]$ & $(1 R, 2 R)$ enantiomer & Sohncke & enantiopure & $e e$ & $0 / 2$ & 7 \\
\hline$\left[\left(\mathrm{UO}_{2}\right)_{4} \mathrm{Rb}_{4}(R-t-1,2-\mathrm{chdc})_{6}(\mathrm{NMP})_{0.5}\left(\mathrm{H}_{2} \mathrm{O}\right)_{3.75}\right]$ & $(1 R, 2 R)$ enantiomer & Sohncke & enantiopure & $e e$ & $0 / 3$ & 7 \\
\hline$\left[\left(\mathrm{UO}_{2}\right)_{4} \mathrm{Rb}_{4}(R-t-1,2 \text {-chdc })_{6}\left(\mathrm{H}_{2} \mathrm{O}\right)_{1.5}\right]$ & $(1 R, 2 R)$ enantiomer & Sohncke & enantiopure & $e e$ & $0 / 2$ & 7 \\
\hline$\left[\left(\mathrm{UO}_{2}\right)_{4} \mathrm{Css}_{4}(t-1,2-\mathrm{chdc})_{6}\left(\mathrm{H}_{2} \mathrm{O}\right)_{3}\right]$ & racemic & centrosymmetric & racemic & $e e$ & 0 & 7 \\
\hline$\left[\left(\mathrm{UO}_{2}\right)_{4} \mathrm{Cs}_{4}(R-t-1,2-\mathrm{chdc})_{6}\left(\mathrm{H}_{2} \mathrm{O}\right)_{4}\right]$ & $(1 R, 2 R)$ enantiomer & Sohncke & enantiopure & $e e$ & $0 / 1$ & 7 \\
\hline$\left[\left(\mathrm{UO}_{2}\right)_{4} \mathrm{Ba}_{2}(R-t-1,2 \text {-chdc })_{6}\left(\mathrm{H}_{2} \mathrm{O}\right)_{8}\right]$ & $(1 R, 2 R)$ enantiomer & chiral & enantiopure & $e e$ & $0 / 3$ & 7 \\
\hline$\left[\left(\mathrm{UO}_{2}\right)_{2} \mathrm{Ag}_{2}(t-1,2-\mathrm{chdc})_{3}\left(\mathrm{H}_{2} \mathrm{O}\right)_{2}\right]$ & racemic & centrosymmetric & racemic & $e e$ & $0 / 3$ & 6 \\
\hline$\left[\left(\mathrm{UO}_{2}\right)_{2} \mathrm{~Pb}(R-t-1,2-\mathrm{chdc})_{3}\left(\mathrm{H}_{2} \mathrm{O}\right)_{4}\right]$ & $(1 R, 2 R)$ enantiomer & chiral & enantiopure & $e e$ & $0 / 3$ & 6 \\
\hline$\left[\left(\mathrm{UO}_{2}\right)_{12} \mathrm{~K}_{5}(R-t-1,2-\mathrm{chdc})_{4}\left(\mathrm{C}_{2} \mathrm{O}_{4}\right)_{10}(18 \mathrm{C} 6)_{5}(\mathrm{OH})\left(\mathrm{H}_{2} \mathrm{O}\right)_{3}\right]$ & $(1 R, 2 R)$ enantiomer & Sohncke & enantiopure & $e e$ & 3 & 11 \\
\hline$\left[\left(\mathrm{UO}_{2}\right)_{12} \mathrm{~K}_{5}(t-1,2 \text {-chdc })_{4}\left(\mathrm{C}_{2} \mathrm{O}_{4}\right)_{10}(18 \mathrm{C} 6)_{5}(\mathrm{OH})\left(\mathrm{H}_{2} \mathrm{O}\right)_{3}\right]$ & racemic & centrosymmetric & racemic & $e e$ & 3 & 11 \\
\hline$\left[\left(\mathrm{UO}_{2}\right)_{8} \mathrm{~K}_{4}(t-1,2-\mathrm{chdc})_{4}\left(\mathrm{C}_{2} \mathrm{O}_{4}\right)_{6}(18 \mathrm{C} 6)_{3}\left(\mathrm{H}_{2} \mathrm{O}\right)_{2}\right]$ & racemic & centrosymmetric & racemic & $e e$ & 3 & 11 \\
\hline$\left[\left(\mathrm{UO}_{2}\right)_{2}(t-1,2 \text {-chdc })_{2}(t-1,2-\text { chdcH })_{2} \mathrm{Ni}(\mathrm{cyclam})\right]$ & racemic & centrosymmetric & racemic & $e e$ & 2 & 12 \\
\hline$[\mathrm{Ni}($ cyclam $)]\left[\left(\mathrm{UO}_{2}\right)_{5}(R-t-1,2-\mathrm{chdc})_{3}(R-t-1,2-\mathrm{chdcH})(\mathrm{O})_{2}\left(\mathrm{CH}_{3} \mathrm{COO}\right)\right]$ & $(1 R, 2 R)$ enantiomer & Sohncke & enantiopure & $e e / a a$ & 2 & 12 \\
\hline$\left[\mathrm{Ni}\left(\mathrm{Me}_{6}\right.\right.$ cyclam $\left.)\right]\left[\mathrm{Ni}\left(\mathrm{Me}_{6}\right.\right.$ cyclam $\left.)\left(\mathrm{H}_{2} \mathrm{O}\right)_{2}\right]\left[\left(\mathrm{UO}_{2}\right)_{2}(t-1,2 \text {-chdc })_{2}(\mathrm{O})\right]_{2}$ & $(1 R, 2 R)$ enantiomer & centrosymmetric & racemic & $e e$ & 0 & 12 \\
\hline$\left[\mathrm{PPh}_{4}\right]\left[\mathrm{UO}_{2}(R-t-1,2-\mathrm{chdc})(\mathrm{HCOO})\right]$ & $(1 R, 2 R)$ enantiomer & Sohncke & enantiopure & $a a$ & 1 & 10 \\
\hline$\left[\mathrm{PPh}_{4}\right]\left[\mathrm{UO}_{2}(S-t-1,2-\mathrm{chdc})(\mathrm{HCOO})\right]$ & racemic & Sohncke & enantiopure (resolved) & $a a$ & 1 & 10 \\
\hline$\left[\mathrm{PPh}_{3} \mathrm{Me}\right]\left[\mathrm{H}_{2} \mathrm{NMe}_{2}\right]_{3}\left[\left(\mathrm{UO}_{2}\right)_{4}(\text { R-t-1,2-chdc })_{6}\right]$ & $(1 R, 2 R)$ enantiomer & Sohncke & enantiopure & $e e$ & 2 & 10 \\
\hline
\end{tabular}

${ }^{a}$ For clarity, free solvent molecules are excluded

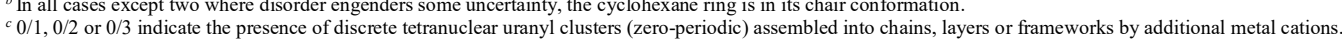


Table 3. Uranyl Ion Complexes with $c$ - and $t-1,3-\operatorname{chdc}^{2-}$, and $c$ - and $t-1,4-\operatorname{chdc}^{2-}$

\begin{tabular}{|c|c|c|c|c|}
\hline compound $^{a}$ & $\begin{array}{l}\text { substituents } \\
\text { orientation }^{b}\end{array}$ & periodicity & interpenetration & ref \\
\hline \multicolumn{5}{|l|}{ 1,3-chde } \\
\hline$\left[\mathrm{UO}_{2}(c-1,3-\mathrm{chdc})\left(\mathrm{H}_{2} \mathrm{O}\right)\right]$ & $e e$ & 2 & & 27 \\
\hline$\left[\left(\mathrm{UO}_{2}\right)_{2}(c-1,3-\mathrm{chdc})_{2}\left(\mathrm{C}_{2} \mathrm{O}_{4}\right)\right]\left[\mathrm{UO}_{2}\left(\mathrm{H}_{2} \mathrm{O}\right)_{5}\right] \cdot(12 \mathrm{C} 4)$ & $e e$ & 1 & & 11 \\
\hline$\left[\left(\mathrm{UO}_{2}\right)_{2}(c-1,3-\mathrm{chdc})(t-1,3-\mathrm{chdc})\left(\mathrm{H}_{2} \mathrm{O}\right)_{3}\right] \cdot(15 \mathrm{C} 5)$ & $e e(c)$ ae $(t)$ & 1 & & 27 \\
\hline$\left[\mathrm{NH}_{4}\right]\left[\mathrm{NBu}_{4}\right]\left[\left(\mathrm{UO}_{2}\right)_{2}(c-1,3-\mathrm{chdc})_{2}(t-1,3-\mathrm{chdc})\right]$ & $e e(c)$ ae $(t)$ & 3 & & this work \\
\hline \multicolumn{5}{|l|}{ 1,4-chdc } \\
\hline$\left[\mathrm{UO}_{2}(t-1,4-\mathrm{chdc})\right]$ & $e e$ & 2 & & 9 \\
\hline$\left[\mathrm{UO}_{2}(t-1,4-\mathrm{chdc})\left(\mathrm{H}_{2} \mathrm{O}\right)_{2}\right]$ & $e e$ & 1 & & 9 \\
\hline$\left[\mathrm{UO}_{2}(c-1,4-\mathrm{chdc})(\mathrm{DMF})\right]$ & ae & 2 & & 9 \\
\hline$\left[\mathrm{UO}_{2}(c-1,4-\mathrm{chdc})(\right.$ bipy $\left.)\right]$ & ae & 1 & & 9 \\
\hline$\left[\mathrm{C}\left(\mathrm{NH}_{2}\right)_{3}\right]_{3}\left[\mathrm{H}_{2} \mathrm{NMe}_{2}\right]\left[\left(\mathrm{UO}_{2}\right)_{4}(c-1,4-\mathrm{chdc})_{6}\right]$ & ae & 3 & & 9 \\
\hline$\left[\mathrm{H}_{2} \mathrm{NMe}_{2}\right]_{2}\left[\left(\mathrm{UO}_{2}\right)_{2}(c-1,4-\mathrm{chdc})_{2}(t-1,4-\mathrm{chdc})\right]$ & $a e(c) e e(t)$ & 1 & & 9 \\
\hline$\left[\mathrm{H}_{2} \mathrm{NMe}_{2}\right]_{2}\left[\left(\mathrm{UO}_{2}\right)_{2}(c-1,4-\mathrm{chdc})(t-1,4-\mathrm{chdc})_{2}\right]$ & $a e(c) e e(t)$ & 2 & threefold & 9 \\
\hline$\left[\mathrm{H}_{2} \mathrm{NMe}_{2}\right]_{2}\left[\left(\mathrm{UO}_{2}\right)_{2}(c, t-1,4-\mathrm{chdc})_{3}\right]$ & $a e(c) e e(t)$ & 3 & threefold & 9 \\
\hline$\left[\mathrm{H}_{2} \mathrm{NMe}_{2}\right]_{2}\left[\left(\mathrm{UO}_{2}\right)_{2}(t-1,4-\mathrm{chdc})_{3}\right]$ & $e e$ & 3 & sixfold & this work \\
\hline$\left[\mathrm{M}(\mathrm{bipy})_{3}\right]\left[\left(\mathrm{UO}_{2}\right)_{2}(c-1,4-\mathrm{chdc})_{3}\right](\mathrm{M}=\mathrm{Co}, \mathrm{Cd})$ & ae & 3 & & 9 \\
\hline$\left[\mathrm{Ni}(\text { bipy })_{3}\right]_{2}\left[\left(\mathrm{UO}_{2}\right)_{4}(c-1,4-\mathrm{chdc})_{2}(t-1,4-\mathrm{chdc})\left(\mathrm{NO}_{3}\right)_{6}\right]$ & $a e(c) e e(t)$ & 0 & & 9 \\
\hline$\left[\mathrm{Cu}(\text { bipy })_{2}\right]_{2}\left[\left(\mathrm{UO}_{2}\right)_{2}(c-1,4-\mathrm{chdc})_{2}(t-1,4-\mathrm{chdc})\right]$ & $a e(c) e e(t)$ & 3 & twofold & 9 \\
\hline$\left[\mathrm{Zn}(\text { bipy })_{3}\right]\left[\left(\mathrm{UO}_{2}\right)_{2}(c-1,4-\mathrm{chdc})_{3}\right]$ & ae & 2 & & 9 \\
\hline$\left[\mathrm{UO}_{2} \mathrm{~Pb}_{2}(c-1,4-\mathrm{chdc})(t-1,4-\mathrm{chdc})_{2}(\text { bipy })_{2}\right]$ & $a e(c) e e / a a(t)$ & 3 & & 9 \\
\hline$\left[\mathrm{PPh}_{4}\right]\left[\mathrm{UO}_{2}(t-1,4-\mathrm{chdc})\left(\mathrm{NO}_{3}\right)\right]$ & $e e$ & 1 & & 10 \\
\hline$\left[\mathrm{PPh}_{4}\right]\left[\mathrm{UO}_{2}(c-1,4-\mathrm{chdc})\left(\mathrm{NO}_{3}\right)\right]$ & ae & 1 & & 10 \\
\hline$\left[\mathrm{PPh}_{4}\right]_{2}\left[\left(\mathrm{UO}_{2}\right)_{2}(t-1,4-\mathrm{chdc})_{3}\right]$ & $e e / a a$ & 2 & & 10 \\
\hline$\left[\mathrm{PPh}_{3} \mathrm{Me}\right]_{2}\left[\left(\mathrm{UO}_{2}\right)_{2}(t-1,4-\mathrm{chdc})_{3}\right]$ & $e e / a a$ & 2 & & 10 \\
\hline$\left[\mathrm{PPh}_{3} \mathrm{Me}_{2}\left[\left(\mathrm{UO}_{2}\right)_{2}(c-1,4-\mathrm{chdc})_{3}\right]\right.$ & ae & 2 & & 10 \\
\hline$\left[\mathrm{PPh}_{4}\right]_{2}\left[\left(\mathrm{UO}_{2}\right)_{2}(t-1,4-\mathrm{chdc})_{2}(c-1,4-\mathrm{chdc})\right]$ & $a e(c)$ ee/aa (t) & 2 & & 10 \\
\hline
\end{tabular}

${ }^{a}$ For clarity, free solvent molecules are excluded.

${ }^{b}$ In all cases except three where disorder engenders some uncertainty, the cyclohexane ring is in its chair conformation.

$c-1,2-\operatorname{chdc}^{2-}, t-1,2-\operatorname{chdc}^{2-}$ under its racemic or $(1 R, 2 R)$ enantiomeric forms, $t-1,4-$ chdc $^{2-}$ and mixtures of the cis and trans isomers of both 1,3- and 1,4-chdc ${ }^{2-}$, the largest number of crystallized complexes were obtained with $t-1,2-\operatorname{chdc}^{2-}$ (32 cases), followed by $c$ - and $t-1,4-\operatorname{chdc}^{2-}$ (20 cases), far above $c-1,2-\operatorname{chdc}^{2-}(9$ cases $)$ and $c$ - and $t-1,3-\operatorname{chdc}^{2-}(4$ cases $)$. This probably reflects the relative positioning of the two carboxylate groups in the two former ligands being better adapted to uranyl complexation. Possibly also the presence of both the cis and trans isomers in the reaction mixtures 
Scheme 1. Coordination Mode of the cis and trans Isomers of 1,2-, 1,3- and 1,4-chdc ${ }^{2-}$ in Homo- and Heterometallic Uranyl Ion Complexes ${ }^{a}$

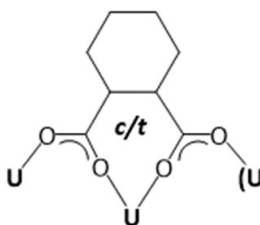

(U)
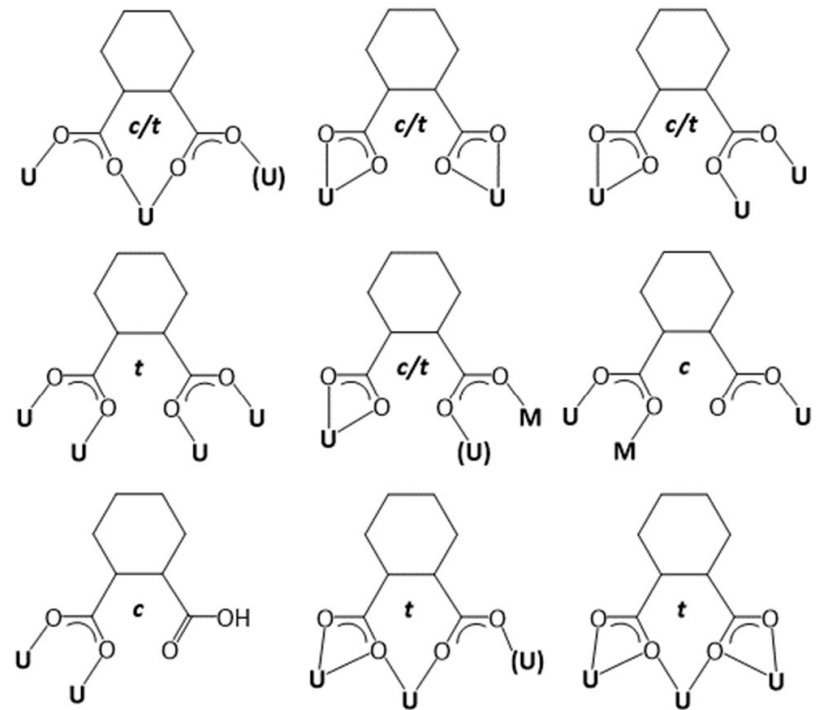

1,2-chdc
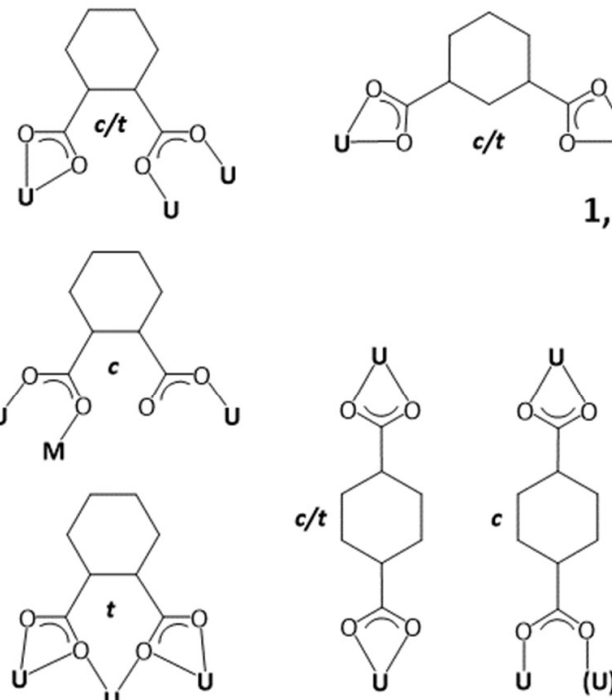

1,3-chdc

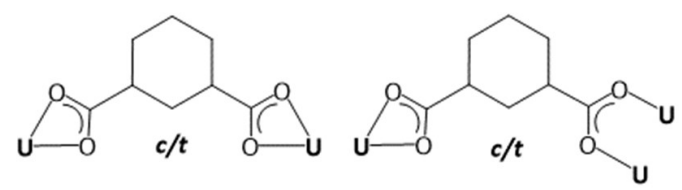

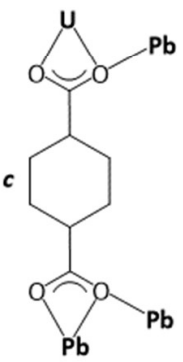

1,4-chdc

${ }^{a}$ Labels in parentheses indicate facultative coordination. $\mathrm{M}=$ additional metal cation.

in the case of 1,3-chdc ${ }^{2-}$ is unfavorable to crystallization (although several complexes with 1,4$\operatorname{chdc}^{2-}$ were also obtained from a cis/trans mixture). In the case of both $c$ - and $t-1,2-\operatorname{chdc}^{2-}$, the most frequent coordination modes involve chelation through the two carboxylate groups, with formation of a seven-membered chelate ring, further bridging of the lateral oxygen atoms giving a maximum number of three complexed metal cations. Other frequent modes are $\operatorname{bis}-\kappa^{2} O, O^{\prime}-$ chelating, $\kappa^{2} O, O^{\prime}$-chelating $/ \mu_{2}-\kappa^{1} O: \kappa^{1} O^{\prime}$-bridging, and bis- $\mu_{2}-\kappa^{1} O: \kappa^{1} O^{\prime}$-bridging. The other, scarcer modes are found in heterometallic complexes. Much less diversity is found with $c$ - and $t$ $1,3-$ chdc $^{2-}$, with only two modes, bis- $\kappa^{2} O, O^{\prime}$-chelating and $\kappa^{2} O, O^{\prime}$-chelating $/ \mu_{2}-\kappa^{1} O: \kappa^{1} O^{\prime}-$ bridging. The same two modes are found with $c-1,4-c_{d h}^{2-}$, and only the former with $t$-1,4-chdc ${ }^{2-}$, and two additional modes are found in a heterometallic uranyl-lead(II) complex. Overall, the number of coordinated cations is between 2 and 4 . Additional geometric variations are induced by the possibilities of axial or equatorial positioning of the carboxylate groups. $c-1,2-$ 
chdc $^{2-}$ is always in the ae form, but, although $t-1,2-\operatorname{chdc}^{2-}$ is most often in the ee form, four cases displaying the $a a$ conformation have been found (one of them in complex 2), a form that is rather rare in metal ion complexes generally, ${ }^{43,44}$ but is present in solution. ${ }^{45}$ This $e e-a a$ transformation turns a mostly convergent into a divergent ligand. $c-1,3-\operatorname{chdc}^{2-}$ is always found in the ee form, in agreement with the results of experiments in solution, ${ }^{45}$ and $t-1,3-\mathrm{chdc}^{2-}$ in the ae one. As for 1,4$\operatorname{chdc}^{2-}$, its cis isomer is always ae and its trans isomer is predominantly ee, but for four cases in which the latter, elongated conformation coexists with the kinked $a a$ one, as found in other MOFs. ${ }^{46}$ Perhaps the only common factor to be discerned in the whole present series is that the cyclohexane ring in the very large majority, if not all cases has a chair conformation, but, as just seen, this does not however restrict its substituents to a particular orientation (axial or equatorial) and free rotation about the $\mathrm{C}-\mathrm{CO}_{2}$ bonds adds a further degree of flexibility to the ligand coordination modes. Worthy of note are also the occurrences of isomerization leading to partial conversion of $c-1,2-$ chdc $^{2-}$ into the trans isomer during the synthesis of complex 2 , and of racemization of $R-t-1,2-$ chdc ${ }^{2-},{ }^{12}$ both processes indicating easy inversion of $>\mathrm{CHCO}_{2} \mathrm{H}$ centres under solvothermal conditions, possibly catalysed by coordination to $\mathrm{U}^{\mathrm{VI}}$.

Due to the generally convergent geometry of their carboxylate groups, $t$ - and $c-1,2-\operatorname{chdc}^{2-}$ are well adapted to the formation of closed, polynuclear species, ${ }^{5}$ as shown by the formation of tetranuclear and octanuclear cages, respectively. ${ }^{6-8}$ In contrast, the divergent $1,4-$ chdc $^{2-}$ ligands are better suited to the formation of triperiodic frameworks, with six such assemblies known. An interesting point here is that these ligands (both cis and trans) are sufficiently elongated to allow interpenetration of frameworks in several cases, the highest degree of interpenetration of 6 being found in the present complex $\mathbf{6}$ which contains only the most elongated trans ee form and a small counterion. Complex $\mathbf{5}$ is a genuine triperiodic framework, and the only one obtained with 1,3chdc $^{2-}$ ligands, thus showing that even in such an unfavorable case the tendency of uranyl ion 
complexes to adopt quasi-planar structures, usually attributed to the coordination sphere of uranyl ion being planar, ${ }^{5,47}$ can be surmounted through the choice of an appropriate counterion. In contrast, $t$ - and $c-1,2-\operatorname{chdc}^{2-}$ appear to be somewhat maladjusted to the design of 3D frameworks, since the only examples known, with the trans isomer only, contain either planar uranyl-containing subunits linked by potassium cations ${ }^{11}$ or tetranuclear uranyl clusters united through coordination of additional metal cations. ${ }^{6,7}$ Notwithstanding the occurrence of zero- and triperiodic structures, mono- and diperiodic assemblies are also numerous in the whole series of compounds, as is natural for ditopic ligands bound to only a moderate number of uranyl cations (often only two). Some interesting species are found here also, such as the helical coordination polymer $\mathbf{1}$, which provides a unique example of a chiral lattice containing the $c-(R, S)-1,2-\operatorname{chdc}^{2-}$ ligand. For the anionic coordination polymers, which represent a significant part of the whole series, particularly in the case of $1,4-$ chdc $^{2-}$, differences in the spatial array and nature of binding sites interacting with the countercations obviously play a role in determining the exact form of the complex but it remains difficult to predict what may be the dominant influence on solubility. Considering the geometric variety of these cyclohexanedicarboxylate ligands and their versatility toward uranyl complexation, this ligand family appears as among the richest for the investigation of uranyl-containing coordination polymers and closed species.

\section{ASSOCIATED CONTENT}

\section{Accession Codes}

CCDC 1948718-1948723 contain the supplementary crystallographic data for this paper. These data can be obtained free of charge via www.ccdc.cam.ac.uk/data_request/cif, or by emailing data_request@ccdc.cam.ac.uk, or by contacting The Cambridge Crystallographic Data Centre, 12 Union Road, Cambridge CB2 1EZ, UK; fax: +44 1223336033. 


\section{AUTHOR INFORMATION}

\section{Corresponding Authors}

*E-mail: pierre.thuery@cea.fr. (P.T.)

*E-mail: harrowfield@unistra.fr. (J.H.)

\section{ORCID}

Pierre Thuéry: 0000-0003-1683-570X

Jack Harrowfield: 0000-0003-4005-740X

\section{Notes}

The authors declare no competing financial interest.

\section{REFERENCES}

1. Wang, K. X.; Chen, J. S. Extended Structures and Physicochemical Properties of Uranyl-Organic Compounds. Acc. Chem. Res. 2011, 44, 531-540.

2. Andrews, M. B.; Cahill, C. L. Uranyl Bearing Hybrid Materials: Synthesis, Speciation, and SolidState Structures. Chem. Rev. 2013, 113, 1121-1136.

3. Loiseau, T.; Mihalcea, I.; Henry, N.; Volkringer, C. The Crystal Chemistry of Uranium Carboxylates. Coord. Chem. Rev. 2014, 266-267, 69-109.

4. Su, J.; Chen, J. S. MOFs of Uranium and the Actinides. Struct. Bond. 2015, 163, 265-296.

5. Thuéry, P.; Harrowfield, J. Recent Advances in Structural Studies of Heterometallic UranylContaining Coordination Polymers and Polynuclear Closed Species. Dalton Trans. 2017, 46, $13660-13667$. 
6. Thuéry, P.; Harrowfield, J. Coordination Polymers and Cage-Containing Frameworks in Uranyl Ion Complexes with rac- and (1R,2R)-trans-1,2-Cyclohexanedicarboxylates: Consequences of Chirality. Inorg. Chem. 2017, 56, 1455-1469.

7. Thuéry, P.; Harrowfield, J. Tetrahedral and Cuboidal Clusters in Complexes of Uranyl and Alkali or Alkaline-Earth Metal Ions with rac- and (1R,2R)-trans-1,2-Cyclohexanedicarboxylate. Cryst. Growth Des. 2017, 17, 2881-2892.

8. Thuéry, P.; Atoini, Y.; Harrowfield, J. Counterion-Controlled Formation of an Octanuclear Uranyl Cage with cis-1,2-Cyclohexanedicarboxylate Ligands. Inorg. Chem. 2018, 57, 6283-6288.

9. Thuéry, P.; Harrowfield, J. Structural Consequences of 1,4-Cyclohexanedicarboxylate Cis/Trans Isomerism in Uranyl Ion Complexes: From Molecular Species to 2D and 3D Entangled Nets. Inorg. Chem. 2017, 56, 13464-13481.

10. Thuéry, P.; Atoini, Y.; Harrowfield, J. Uranyl-Organic Coordination Polymers with trans-1,2-, trans-1,4-, and cis-1,4-Cyclohexanedicarboxylates: Effects of Bulky $\mathrm{PPh}_{4}^{+}$and $\mathrm{PPh}_{3} \mathrm{Me}^{+}$ Counterions. Cryst. Growth Des. 2018, 18, 2609-2619.

11. Thuéry, P.; Atoini, Y.; Harrowfield, J. Crown Ethers and Their Alkali Metal Ion Complexes as Assembler Groups in Uranyl-Organic Coordination Polymers with cis-1,3-, cis-1,2-, and trans1,2-Cyclohexanedicarboxylates. Cryst. Growth Des. 2018, 18, 3167-3177.

12. Thuéry, P.; Harrowfield, J. $[\mathrm{Ni}(\text { cyclam })]^{2+}$ and $\left[\mathrm{Ni}\left(R, S-\mathrm{Me}_{6} \text { cyclam }\right)\right]^{2+}$ as Linkers or Counterions In Uranyl-Organic Species with cis- and trans-1,2-Cyclohexanedicarboxylate Ligands. Cryst. Growth Des. 2018, 18, 5512-5520.

13. Kimura, K.; Watanabe, Y.; Suda, T.; Senda, H.; Hosoi, S.; Ohta, T.; Kunimoto, K. K. Crystal Structure of $(1 R, 2 R)$-trans-1,2-Cyclohexanedicarboxylic Acid- $(R)$-1-Phenylethylamine Salt. Anal. Sci. 1999, 15, 609-610.

14. Hooft, R. W. W. COLLECT, Nonius BV: Delft, The Netherlands, 1998. 
15. Otwinowski, Z.; Minor, W. Processing of X-Ray Diffraction Data Collected in Oscillation Mode. Methods Enzymol. 1997, 276, 307-326.

16. Sheldrick, G. M. SHELXT - Integrated Space-Group and Crystal-Structure Determination. Acta Crystallogr., Sect. A 2015, 71, 3-8.

17. Sheldrick, G. M. Crystal Structure Refinement with SHELXL. Acta Crystallogr., Sect. C 2015, $71,3-8$.

18. Farrugia, L. J. WinGX and ORTEP for Windows: an Update. J. Appl. Crystallogr. 2012, 45, 849854.

19. Momma, K.; Izumi, F. VESTA 3 for Three-Dimensional Visualization of Crystal, Volumetric and Morphology Data. J. Appl. Crystallogr. 2011, 44, 1272-1276.

20. Blatov V. A.; Shevchenko, A. P.; Proserpio, D. M. Applied Topological Analysis of Crystal Structures with the Program Package ToposPro. Cryst. Growth Des. 2014, 14, 3576-3586.

21. Spek, A. L. Structure Validation in Chemical Crystallography. Acta Crystallogr., Sect. D 2009, $65,148-155$.

22. Thuéry, P.; Masci, B. Uranyl-Organic Frameworks with 1,2,3,4-Butanetetracarboxylate and 1,2,3,4-Cyclobutanetetracarboxylate Ligands. Cryst. Growth Des. 2008, 8, 3430-3436.

23. Smith, G.; Wermuth, U. D.; Williams, M. L. Resolution of the Chiral $(1 R, 2 S)$ Enantiomer of cisCyclohexane-1,2-dicarboxylic Acid in the Brucinium Salt 2,3-Dimethoxy-10-oxostrychnidinium (1R,2S)-2-carboxycyclohexane-1-carboxylate Dihydrate. J. Chem. Crystallogr. 2012, 42, 555559.

24. Dance, I.; Scudder, M. Supramolecular Motifs: Concerted Multiple Phenyl Embraces between $\mathrm{Ph}_{4} \mathrm{P}^{+}$Cations are Attractive and Ubiquitous. Chem. Eur. J. 1996, 2, 481-486.

25. Etter, M. C.; MacDonald, J. C.; Bernstein, J. Graph-Set Analysis of Hydrogen-Bond Patterns in Organic Crystals. Acta Crystallogr., Sect. B 1990, 46, 256-262. 
26. Bernstein, J.; Davis, R. E.; Shimoni, L.; Chang, N. L. Patterns in Hydrogen Bonding: Functionality and Graph Set Analysis in Crystals. Angew. Chem. Int. Ed. 1995, 34, 1555-1573.

27. Thuéry, P. Two Novel Uranyl-Organic Frameworks with Cyclohexane-1,3-Dicarboxylate Ligands. CrystEngComm 2009, 11, 232-234.

28. Thuéry, P.; Harrowfield, J. Variations on the Honeycomb Topology: From Triangular- and Square-Grooved Networks to Tubular Assemblies in Uranyl Tricarballylate Complexes. Cryst. Growth Des. 2017, 17, 963-966.

29. Thuéry, P.; Atoini, Y.; Harrowfield, J. Closed Uranyl-Dicarboxylate Oligomers: A Tetranuclear Metallatricycle with Uranyl Bridgeheads and 1,3-Adamantanediacetate Linkers. Inorg. Chem. 2018, 57, 7932-7939.

30. Liu, C.; Gao, C. Y.; Yang, W.; Chen, F. Y.; Pan, Q. J.; Li, J.; Sun, Z. M. Entangled Uranyl Organic Frameworks with (10,3)-b Topology and Polythreading Network: Structure, Luminescence, and Computational Investigation. Inorg. Chem. 2016, 55, 5540-5548.

31. Blatov, V. A.; Carlucci, L.; Ciani, G.; Proserpio, D. M. Interpenetrating Metal-Organic and Inorganic 3D Networks: a Computer-Aided Systematic Investigation. Part I. Analysis of the Cambridge Structural Database. CrystEngComm 2004, 6, 377-395.

32. Alexandrov, E. V.; Blatov, V. A.; Kochetkov, A. V.; Proserpio, D. M. Underlying Nets in ThreePeriodic Coordination Polymers: Topology, Taxonomy and Prediction from a Computer-Aided Analysis of the Cambridge Structural Database. CrystEngComm 2011, 13, 3947-3958.

33. Wu, H.; Yang, J.; Su, Z. M.; Batten, S. R.; Ma, J. F. An Exceptional 54-Fold Interpenetrated Coordination Polymer with $10^{3}$-srs Network Topology. J. Am. Chem. Soc. 2011, 133, 1140611409.

34. Batten, S. R.; Robson, R. Interpenetrating Nets: Ordered, Periodic Entanglement. Angew. Chem. Int. Ed. 1998, 37, 1460-1494. 
35. Batten, S. R. Topology of Interpenetration. CrystEngComm 2001, 18, 1-7.

36. Alexandrov, E. V.; Blatov, V. A.; Proserpio, D. M. A Topological Method for the Classification of Entanglements in Crystal Networks. Acta Crystallogr., Sect. A 2012, 68, 484-493.

37. Liu, C.; Chen, F. Y.; Tian, H. R.; Ai, J.; Yang, W.; Pan, Q. J.; Sun, Z. M. Interpenetrated Uranyl-Organic Frameworks with bor and pts Topology: Structure, Spectroscopy, and Computation. Inorg. Chem. 2017, 56, 14147-14156.

38. Hu, K. Q.; Wu, Q. Y.; Mei, L.; Zhang, X. L.; Ma, L.; Song, G.; Chen, D. Y.; Wang, Y. T.; Chai, Z. F.; Shi, W. Q. Novel Viologen Derivative Based Uranyl Coordination Polymers Featuring Photochromic Behaviors. Chem. Eur. J. 2017, 23, 18074-18083.

39. Wang, S.; Mei, L.; Yu, J. P.; Hu, K. Q.; Liu, Z. R.; Chai, Z. F.; Shi, W. Q. Large-Pore Layered Networks, Polycatenated Frameworks, and Three-Dimensional Frameworks of Uranyl Tri(biphenyl)amine/Tri(phenyl)amine Tricarboxylate: Solvent-/Ligand-Dependent Dual Regulation. Cryst. Growth Des. 2018, 18, 4347-4356.

40. Liu, C.; Wang, C.; Sun, Z. M. Conformational 2-Fold Interpenetrated Uranyl Supramolecular Isomers Based on (6,3) Sheet Topology: Structure, Luminescence, and Ion Exchange. Inorg. Chem. 2018, 57, 15370-15378.

41. Thuéry, P.; Atoini, Y.; Harrowfield, J. Structure-Directing Effects of Counterions in Uranyl Ion Complexes with Long-Chain Aliphatic $\alpha, \omega$-Dicarboxylates: 1D to Polycatenated 3D Species. Inorg. Chem. 2019, 58, 567-580.

42. An, S. W.; Mei, L.; Hu, K. Q.; Li, F. Z.; Xia, C. Q.; Chai, Z. F.; Shi, W. Q. Bipyridine-Directed Syntheses of Uranyl Compounds Containing Semirigid Dicarboxylate Linkers: Diversity and Consistency in Uranyl Speciation. Inorg. Chem. 2019, 58, 6934-6945. 
43. Hernández-Ahuactzi, I. F.; Höpfl, H.; Barba, V.; Román-Bravo, P.; Zamudio-Rivera, L. S.; Beltrán, H. I. Pore-Size Tuning in Double-Pillared Metal-Organic Frameworks Containing Cadmium Clusters. Eur. J. Inorg. Chem. 2008, 2746-2755.

44. Yue, Q.; Huang, Q.; Gao, Y. Y.; Gao, E. Q. Homochiral Coordination Polymers from a Chiral Dicarboxylic Acid and Dipyridyl Ligands: Structural Diversity, Photoluminescence and Magnetic Properties. Inorg. Chim. Acta 2016, 443, 110-117.

45. Garza, A. J.; Nag, M.; Carroll, W. R.; Goddard, W. A. III; Roberts, J. D. Conformational Preferences of trans-1,2- and cis-1,3-Cyclohexanedicarboxylic Acids in Water and Dimethyl Sulfoxide as a Function of the Ionization State As Determined from NMR Spectroscopy and Density Functional Theory Quantum Mechanical Calculations. J. Am. Chem. Soc. 2012, 134, $14772-14780$.

46. Niekiel, F.; Lannoeye, J.; Reinsch, H.; Munn, A. S.; Heerwig, A.; Zizak, I.; Kaskel, S.; Walton, R. I.; de Vos, D.; Llewellyn, P.; Lieb, A.; Maurin, G.; Stock; N. Conformation-Controlled Sorption Properties and Breathing of the Aliphatic Al-MOF $[\mathrm{Al}(\mathrm{OH})(\mathrm{CDC})]$. Inorg. Chem. 2014, 53, $4610-4620$.

47. Burns, P. C. $\mathrm{U}^{6+}$ Minerals and Inorganic Compounds: Insights into an Expanded Structural Hierarchy of Crystal Structures. Can Mineral. 2005, 43, 1839-1894. 


\section{Uranyl Ion-Containing Polymeric Assemblies with cis/trans Isomers}

of 1,2-, 1,3- and 1,4-Cyclohexanedicarboxylates, Including a Helical Chain and a Sixfold-Interpenetrated Framework

Pierre Thuéry and Jack Harrowfield

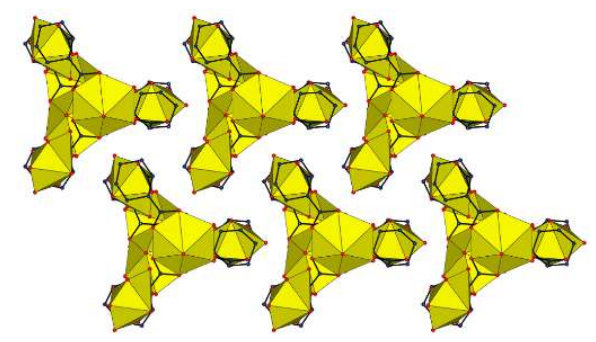

Different cyclohexanedicarboxylate isomers were used in conjunction with diverse counterions to generate mono-, di- and triperiodic uranyl ion-containing coordination polymers. Particularly notable are a helical arrangement involving the $c i s-1,2$ isomer, the first 3D framework with the cis- and trans-1,3 isomers, and a 3D assembly displaying sixfold-interpenetration with the trans-1,4 isomer. 